Journal of Computational Acoustics, Vol. 25, No. 1 (2017) 1750003 (24 pages)

(C) The Author(s)

DOI: $10.1142 / \mathrm{S} 0218396 \mathrm{X} 17500035$

\title{
An Adjoint Operator Approach for Sensitivity Analysis of Radiated Sound Power in Fully Coupled Structural-Acoustic Systems
}

\author{
Leilei Chen \\ College of Civil Engineering, Xinyang Normal University \\ Xinyang 464000, Henan, P. R. China \\ chenllei@mail.ustc.edu.cn \\ Steffen Marburg \\ Institute of Vibroacoustics of Vehicles and Machines \\ Faculty of Mechanical Engineering \\ Technical University of Munich, Boltzmannstr. 15 \\ 85748 Garching bei München, Germany \\ steffen.marburg@tum.de \\ Haibo Chen \\ CAS Key Laboratory of Mechanical Behavior and Design of Materials \\ Department of Modern Mechanics \\ University of Science and Technology of China \\ Hefei 230026, Anhui, P. R. China \\ hbchen@ustc.edu.cn \\ Hao Zhang and Hongbo Gao* \\ College of Civil Engineering, Xinyang Normal University \\ Xinyang 464000, Henan, P. R. China \\ *gaohong0402@sina.com
}

Received 17 May 2016

Accepted 29 August 2016

Published 23 March 2017

Full interaction between structural and fluid domains must be considered for light structures immersed in heavy fluid (e.g. thin steel shells in water). The structural-acoustic design sensitivity analysis provides information on the effect of the design variable on acoustic performance, which makes it a key step for noise control and structural-acoustic optimization. This study uses the finite element method (FEM) to model the structure domain, while the fast multipole boundary element method (BEM) is applied to the exterior acoustic domain. An adjoint operator approach is developed to calculate the sensitivity of the radiated sound power with respect to the design variables,

This is an Open Access article published by World Scientific Publishing Company. It is distributed under the terms of the Creative Commons Attribution 4.0 (CC-BY) License. Further distribution of this work is permitted, provided the original work is properly cited. 


\title{
L. Chen et al.
}

\begin{abstract}
which can be any structural or fluid parameter (e.g. fluid or structural density, Poisson's ratio, Young's modulus, and geometric measures). Numerical examples are presented to demonstrate the validity and efficiency of the proposed algorithm.
\end{abstract}

Keywords: Fluid-structure interaction; FE/FMBE coupling; design sensitivity analysis; adjoint operator approach.

\section{Introduction}

Passive noise control by modification of structure geometry moves more and more into the field of vision for designers. This structural-acoustic optimization shows high potential in minimization of radiated noise especially for thin shell geometries. Acoustic design sensitivity analysis can provide information on how the geometry change affects the acoustic performance of the given structure, so it is an important step of the acoustic design and optimization processes. An overview on developments in structural-acoustic optimization for passive noise control was presented by Marburg. ${ }^{1}$ The global finite difference method (FDM) has been widely applied to the structural-acoustic optimization due to its easiness in implementation, see Refs. 2-4, while analytic and semi-analytic sensitivity analyses are distinguished to the global FDM. These categorizations have been sufficiently reviewed and discussed by Haftka and Adelmann, ${ }^{5}$ see also Refs. 1 and 6 . It has been clear that analytic and semi-analytic sensitivity analyses are significantly more accurate than the global FDM and typically require less computational costs. In recent years, the analytic sensitivity analysis as a direct differentiation method has been applied to structural-acoustic problems for elastic structures immersed in heavy fluid. ${ }^{7,8}$ However, the efficiency of this method reduces significantly when many design variables are taken into account concurrently. To address this problem, the adjoint approach is considered, which has been applied to structural-acoustic problems in weak coupling. ${ }^{9,10}$

Most applications of fully coupled structural-acoustic problems are time consuming. Accordingly, numerous methods have been developed to make such analysis as efficient as possible. ${ }^{11}$ The finite element method (FEM) is frequently used to model structural parts because of its high flexibility and applicability to large-scale complex problems. The boundary element method (BEM) is frequently preferred to model the sound field and thus avoid meshing the fluid domain. The coupled finite element/boundary element (FE/BE) approach has been used in many applications (e.g. Refs. 11-18). However, conventional BEM is known to be computationally costly because the system matrix is dense and nonsymmetric. This results in the memory requirements and computational complexity of $O\left(N^{2}\right)$, assuming an iterative solution such as the generalized minimal residual method (GMRES) ${ }^{19,20}$ of the system of equations. Fast BEMs, such as the fast multipole (FM) method ${ }^{11,21-29}$ and the adaptive cross approximation technique, ${ }^{30,31}$ have been applied to accelerate the solution of the Kirchhoff-Helmholtz integral equation. Therefore, the coupling algorithm based on the FE/fast BE method can be effectively applied to solve large-scale fluid-structure interaction problems. ${ }^{7,8,11,32-36}$

Unlike sound pressure, sound power is neither room dependent nor distance dependent. Sound power belongs strictly to the sound source. Sound pressure is a measurement at a 
point in space near the source, while sound power is the total power produced by the source in all directions. The minima of the cost functions that represent the overall radiated sound power are determined by applying the gradient-based optimization techniques in Ref. 37, which is concerned with the optimization of the resonance changer for a submarine and is of great importance in practice. However, no fast algorithm is applied to accelerate the solution of the coupled system of equation. In this work, following our previous research in fully coupled FEM/FMBEM sensitivity analysis, ${ }^{7,8}$ an adjoint operator approach is developed for the radiated sound power sensitivity analysis in fully coupled structural-acoustic systems, where the selected design variable can be as fluid or structural density, Poisson's ratio, Young's modulus, and structural geometric parameters. The derivatives of the vectors of nodal displacement and sound pressure on the interaction surface are obtained by directly differentiating the coupled system of equations with respect to the design variables. The formulation of the derivative of the radiated sound power based on the adjoint operator approach is derived. Through the adjoint operator approach, the numerical efficiency of the sensitivity analysis can be significantly improved when multiple design variables should be considered. Numerical examples are presented to demonstrate the validity and correctness of the present algorithm.

A harmonic time dependence of $e^{-i \omega t}$ is assumed throughout this paper.

\section{Evaluation of Radiated Sound Power}

The emitted sound power $P$ for noise radiation into open domains can be expressed as follows:

$$
P(\omega)=\frac{1}{2} \int_{A} \Re\left\{p(\mathbf{y}, \omega) v_{f}^{*}(\mathbf{y}, \omega)\right\} d A(\mathbf{y}),
$$

where $p$ is the sound pressure, $v_{f}$ is the particle velocity, ( ${ }^{*}$ represents the conjugate complex quantity, and $\Re\{\}$ denotes the real part. The real part of the complex sound power is radiated into the acoustic far field, whereas the imaginary part only contributes to the evanescent near field. $A$ is an arbitrary closed surface around the radiator. Since a BEM formulation for the fluid as applied in this paper supplies the sound pressure and the particle velocity on the structural surface directly, it is convenient to use this surface $\Gamma$ to substitute for $A$ for sound power evaluation.

Discretization of Eq. (1) leads to a matrix expression for sound power, which is given as follows:

$$
P(\omega)=\frac{1}{2} \Re\left\{\mathbf{p}^{T} \mathbf{S v}_{f}^{*}\right\},
$$

where $\mathbf{S}$ denotes the boundary mass matrix $^{38}$ and is given as follows:

$$
\mathbf{S}=\int \mathbf{N}_{f}^{T} \mathbf{N}_{f} d \Gamma .
$$

Accordingly, $\mathbf{N}_{f}$ is a row vector that contains BEM interpolation functions on $\Gamma$. The particle velocity of the fluid $\mathbf{v}_{f}$ can be expressed as a function of the structural displacement $\mathbf{u}$, 


\section{Chen et al.}

as follows:

$$
\mathbf{v}_{f}=\mathbf{S}^{-1} \mathbf{C}_{f s} \mathbf{u}
$$

where the coupling matrix $\mathbf{C}_{f s}$ transforms the structural degrees of freedom to the degrees of freedom of the fluid and is written as follows:

$$
\mathbf{C}_{f s}=-i \omega \int \mathbf{N}_{f}^{T} \mathbf{n} \mathbf{N}_{s} d \Gamma
$$

where $\mathbf{N}_{s}$ represents the FEM basis functions and $\mathbf{n}$ denotes the surface normal vector. The radiated sound power is written by substituting Eq. (4) into Eq. (2) as follows:

$$
P(\omega)=\frac{1}{2} \Re\left\{\mathbf{p}^{T} \mathbf{C}_{f_{s}} \mathbf{u}^{*}\right\} .
$$

The nodal values of the sound pressure $\mathbf{p}$ and the structural displacements $\mathbf{u}$ are obtained from the solution of the coupled structural-acoustic system of equations. This system of equations comprises a block of equations based on the FE formulation for the structural vibrations and another block based on the BE formulation of the acoustic domain. The structural block is given as follows ${ }^{1,15}$ :

$$
\mathbf{A u}=\mathbf{f}_{s}+\mathbf{C}_{s f} \mathbf{p}
$$

with $\mathbf{A}=\mathbf{K}+i \omega \mathbf{C}-\omega^{2} \mathbf{M}$ (with $\mathbf{K}, \mathbf{C}$ and $\mathbf{M}$ being the stiffness, the damping and the mass matrices of the structure, respectively) as the dynamic stiffness matrix, $\mathbf{f}_{s}$ the nodal force vector and $\mathbf{C}_{s f}=\int \mathbf{N}_{s}^{T} \mathbf{n} \mathbf{N}_{f} d \Gamma$. The acoustic block which is based on the BE formulation reads as ${ }^{1,38}$

$$
\mathbf{H p}=\mathbf{G v}_{f}+\mathbf{p}_{i} .
$$

Matrices $\mathbf{H}$ and $\mathbf{G}$ are the frequency dependent BEM coefficient matrices, whereas vector $\mathbf{p}_{i}$ contains the nodal values of the incident pressure field.

The fully coupled system of equations of an elastic structure submerged in a heavy fluid is obtained by combining Eqs. (7) and (8) as follows:

$$
\left[\begin{array}{cc}
\mathbf{A} & -\mathbf{C}_{s f} \\
-\mathbf{G S}^{-1} \mathbf{C}_{f s} & \mathbf{H}
\end{array}\right]\left[\begin{array}{l}
\mathbf{u} \\
\mathbf{p}
\end{array}\right]=\mathbf{B}\left[\begin{array}{l}
\mathbf{u} \\
\mathbf{p}
\end{array}\right]=\left[\begin{array}{l}
\mathbf{f}_{s} \\
\mathbf{p}_{i}
\end{array}\right] .
$$

Theoretically, this system of equations can either be directly or iteratively solved. However, direct solvers are likely to be inefficient because the system matrix will be large and non-Hermitian. While the iterative solver directly applied to the system in Eq. (9) (e.g. GMRES ${ }^{19}$ ) exhibits poor convergence.

An applicable method is to substitute the $\mathrm{FE}$ formulation into the BE equation to generate a reduced system of equations as follows ${ }^{12,39}$ :

$$
\left(\mathbf{H}-\mathbf{G} \mathbf{Y}_{c}\right) \mathbf{p}=\mathbf{G S}^{-1} \mathbf{C}_{f s} \mathbf{A}^{-1} \mathbf{f}_{s}+\mathbf{p}_{i},
$$

where $\mathbf{Y}_{c}=\mathbf{S}^{-1} \mathbf{C}_{f s} \mathbf{A}^{-1} \mathbf{C}_{s f}$ is the coupling admittance matrix that is equivalent to a nonlocal boundary condition for the acoustic problem. ${ }^{39}$ Directly providing $\mathbf{A}^{-1}$ in Eq. (10) 
is challenging. The term $\mathbf{A}^{-1} \mathbf{f}_{s}$ represents solution $\mathbf{x}$ of the linear system of equations $\mathbf{A x}=\mathbf{f}_{s}$. This symmetric and frequency-dependent system is easily solved using a sparse direct solver. The GMRES solver in this work requires the matrix-vector product of system matrix $\mathbf{H}-\mathbf{G} \mathbf{Y}_{c}$ and the current iteration $\mathbf{p}_{k}$ which can be split into $\mathbf{H} \mathbf{p}_{k}$ minus $\mathbf{G} \mathbf{Y}_{c} \mathbf{p}_{k}$. The latter term is equal to $\mathbf{G S}^{-1} \mathbf{C}_{f s} \mathbf{A}^{-1} \mathbf{C}_{s f} \mathbf{p}$ which implies that either two more systems of equations must be solved in every step of the iterative solution of Eq. (10) or inverse matrices $\mathbf{S}^{-1}$ and $\mathbf{A}^{-1}$ must be supplied. Supplying $\mathbf{S}^{-1}$ is easy if discontinuous BEs are used. $\mathbf{S}$ is diagonal and positive real in the case of constant elements. $\mathbf{S}$ will be block diagonal and easy to invert in the case of higher-order elements. $\mathbf{A}^{-1}$ is multiplied with $\mathbf{z}=\mathbf{C}_{s f} \mathbf{p}_{k}$. Hence, the situation is similar to that described earlier as the required solution of $\mathbf{A y}=\mathbf{z}$. This solution must also be supplied in each iteration of the solution process of Eq. (10). This process will be time-consuming for complicated practical structures due to a large number of iterations needed. An adapted modal reduction method can be used to overcome this difficulty instead of a direct solution. ${ }^{40}$ Another possibility of using a factorization-based solver, such as an LU for directly solving $\mathbf{A}^{-1}$ also exists. ${ }^{34}$ These methods should be used only once. The inverted matrix $\mathbf{A}^{-1}$ can be reused in each iteration step. After solving Eq. (10) and substituting the solution of vector p into Eq. (7), it is easy to obtain the solution of vector $\mathbf{u}$. The sound power is finally computed by evaluating Eq. (6).

System matrix $\mathbf{H}-\mathbf{G Y}_{c}$ is fully populated and non-Hermitian. As mentioned in the preceding discussion, an iterative solver (e.g. GMRES) requires the evaluation of a matrixvector product. Under the $N \times N$ matrix, the matrix-vector product requires $O\left(N^{2}\right)$ operations and memory. In the study, the multilevel FM method was developed to accelerate the BEM solution by approximating this matrix-vector product. This approximation can be applied when evaluating the matrix vector products $\mathbf{H p}_{k}$ and $\mathbf{G}\left(\mathbf{Y}_{c} \mathbf{p}_{k}\right)$.

\section{Sensitivity of Radiated Sound Power}

Differentiating Eq. (6) with respect to design variable $\vartheta$, the sound power sensitivity is written as

$$
\frac{\partial P}{\partial \vartheta}=\frac{1}{2} \Re\left\{\left(\frac{\partial \mathbf{p}}{\partial \vartheta}\right)^{T} \mathbf{w}_{1}+\mathbf{p}^{T} \frac{\partial \mathbf{C}_{f s}}{\partial \vartheta} \mathbf{u}^{*}+\mathbf{w}_{2}^{T}\left(\frac{\partial \mathbf{u}}{\partial \vartheta}\right)^{*}\right\}
$$

where $\mathbf{w}_{1}=\mathbf{C}_{f s} \mathbf{u}^{*}$ and $\mathbf{w}_{2}^{T}=\mathbf{p}^{T} \mathbf{C}_{f s}$. In what follows, the expression

$$
\Re\left\{\mathbf{w}_{2}^{T}\left(\frac{\partial \mathbf{u}}{\partial \vartheta}\right)^{*}\right\}=\Re\left\{\mathbf{w}_{2}^{H} \frac{\partial \mathbf{u}}{\partial \vartheta}\right\}
$$

will be used. Superscript ()$^{H}$ denotes the transposed conjugate complex. By applying this expression to Eq. (11), sound power sensitivity is obtained as follows:

$$
\frac{\partial P}{\partial \vartheta}=\frac{1}{2} \Re\left\{\mathbf{w}_{1}^{T} \frac{\partial \mathbf{p}}{\partial \vartheta}+\mathbf{p}^{T} \frac{\partial \mathbf{C}_{f s}}{\partial \vartheta} \mathbf{u}^{*}+\mathbf{w}_{2}^{H} \frac{\partial \mathbf{u}}{\partial \vartheta}\right\} .
$$




\section{Chen et al.}

The implicit differentiation of Eq. (9) with respect to design variable $\vartheta$ and isolating the resulting sensitivities of structural displacement and sound pressure lead to the following

$$
\left[\begin{array}{l}
\frac{\partial \mathbf{u}}{\partial \vartheta} \\
\frac{\partial \mathbf{p}}{\partial \vartheta}
\end{array}\right]=\mathbf{B}^{-1} \mathbf{r}
$$

where

$$
\mathbf{r}=\left[\begin{array}{c}
\frac{\partial \mathbf{f}_{s}}{\partial \vartheta} \\
\frac{\partial \mathbf{p}_{i}}{\partial \vartheta}
\end{array}\right]-\frac{\partial \mathbf{B}}{\partial \vartheta}\left[\begin{array}{l}
\mathbf{u} \\
\mathbf{p}
\end{array}\right]
$$

and

$$
\frac{\partial \mathbf{B}}{\partial \vartheta}=\left[\begin{array}{cc}
\frac{\partial \mathbf{A}}{\partial \vartheta} & -\frac{\partial \mathbf{C}_{s f}}{\partial \vartheta} \\
-\frac{\partial\left(\mathbf{G S}^{-1} \mathbf{C}_{f s}\right)}{\partial \vartheta} & \frac{\partial \mathbf{H}}{\partial \vartheta}
\end{array}\right]
$$

Subsequently, Eq. (14) is multiplied by column matrix $\mathbf{d}^{T}$ from the left. This matrix is selected so that the left side of Eq. (14) coincides with the sum of the first and third terms at the right side of Eq. (13) such that

$$
\mathbf{w}_{1}^{T} \frac{\partial \mathbf{p}}{\partial \vartheta}+\mathbf{w}_{2}^{H} \frac{\partial \mathbf{u}}{\partial \vartheta}=\mathbf{d}^{T}\left[\begin{array}{l}
\frac{\partial \mathbf{u}}{\partial \vartheta} \\
\frac{\partial \mathbf{p}}{\partial \vartheta}
\end{array}\right]=\mathbf{d}^{T} \mathbf{B}^{-1} \mathbf{r}
$$

where

$$
\mathbf{d}=\left[\begin{array}{c}
\mathbf{w}_{2}^{*} \\
\mathbf{w}_{1}
\end{array}\right]
$$

By substituting Eq. (17) into Eq. (13), sound power sensitivity is obtained as follows:

$$
\frac{\partial P}{\partial \vartheta}=\frac{1}{2} \Re\left\{\mathbf{d}^{T} \mathbf{B}^{-1} \mathbf{r}+\mathbf{p}^{T} \frac{\partial \mathbf{C}_{f s}}{\partial \vartheta} \mathbf{u}^{*}\right\} .
$$

Sound power sensitivity is composed of two terms. The first term $\mathbf{d}^{T} \mathbf{B}^{-1} \mathbf{r}$ requires solving a system of equations, which can either be chosen similar to those in Eq. (9) (i.e. Bz̃z = r) or as an adjoint operator approach that solves $\mathbf{B}^{T} \mathbf{z}=\mathbf{d}$. Accordingly, Eq. (15) states that $\mathbf{r}$ depends on the derivatives of certain terms with respect to design variable $\vartheta$, whereas $\mathbf{d}$ does not. Consequently, $m$ design variables $\vartheta_{j}$ with $j=1,2, \ldots, m$ will produce $m$ right sides $\mathbf{r}$, whereas the system

$$
\mathbf{B}^{T} \mathbf{z}=\mathbf{d}
$$


provides only one right side. Only one solution of the system in Eq. (20) is required to determine the first term of sound power sensitivity in Eq. (19) because evaluating the radiated sound power requires the computation of $\mathbf{u}$ and $\mathbf{p}$. Scalar products $\mathbf{z}^{T} \mathbf{r}\left(\vartheta_{k}\right)$ are typically computationally less expensive. The second term in Eq. (19) disappears in many design variables. Structural and acoustic material data can be mentioned, but also any structural parameters which do not modify the interface geometry between structure and fluid because for these parameters $\frac{\partial \mathbf{C}_{f s}}{\partial \vartheta}=0$. The term $\frac{\partial \mathbf{C}_{f s}}{\partial \vartheta}$ does not disappear in case the design variable changes the shape of the interface and is obtained as follows:

$$
\frac{\partial \mathbf{C}_{f s}}{\partial \vartheta}=\int \frac{\partial \mathbf{N}_{f}^{T}}{\partial \vartheta} \mathbf{n} \mathbf{N}_{s} d \Gamma+\int \mathbf{N}_{f}^{T} \frac{\partial \mathbf{n}}{\partial \vartheta} \mathbf{N}_{s} d \Gamma+\int \mathbf{N}_{f}^{T} \mathbf{n} \frac{\partial \mathbf{N}_{s}}{\partial \vartheta} d \Gamma+\int \mathbf{N}_{f}^{T} \mathbf{n} \mathbf{N}_{s} \frac{\partial d \Gamma}{\partial \vartheta}
$$

The term $\frac{\partial d \Gamma}{\partial \vartheta}$ is expressed as follows:

$$
\frac{\partial d \Gamma}{\partial \vartheta}=\left[\frac{\partial^{2} y_{i}}{\partial \vartheta \partial y_{i}}-\frac{\partial^{2} y_{i}}{\partial \vartheta \partial y_{j}} n_{i}(y) n_{j}(y)\right] d \Gamma
$$

where $\frac{\partial y_{i}}{\partial \vartheta}$ is evaluated when the boundary of the analyzed domain is fully parameterized with a shape design variable. Establishing an exact analytical representation of the sensitivity of $\mathbf{C}_{f s}$ is possible but challenging. However, a simple and applicable method involves using finite differences to overcome this difficulty. For example, $\frac{\partial \mathbf{C}_{f s}}{\partial \vartheta}$ can be calculated using forward differences with a small perturbation $\Delta \vartheta$ as follows

$$
\frac{\partial \mathbf{C}_{f s}}{\partial \vartheta}=\frac{\mathbf{C}_{f s}(\vartheta+\Delta \vartheta)-\mathbf{C}_{f s}(\vartheta)}{\Delta \vartheta} .
$$

As discussed in the introduction, this method is a semi-analytical method because it determines the sensitivities of both $\mathbf{C}_{f s}$ and the radiated sound power in Eq. (19). For sensitivities of the sound power level, one can refer to Ref. 1.

\section{Elastic Spherical Shell Excited by a Unit Force}

\subsection{Radiated sound power}

Testing a method and its implementation is a reasonable and common practice. The test is usually conducted by comparing the numerical solution with the analytical one if the latter is available. New methods in elastoacoustics are frequently validated using submerged spheres. ${ }^{17,18,34,36,41}$ This technique is continued in this section, where an elastic spherical shell with radius $r$ is used as an example to test the proposed algorithm.

The spherical shell is excited by a single concentrated force $F$ at point $A$, see configuration in Fig. 1. Angle $\theta$ represents the central angle between the calculated point and the point of excitation, i.e. point $A$. The specific configuration herein considers a sphere made of steel submerged in water. The material data for structure and fluid and the geometrical data are listed in Table 1 . These data are similar to those presented by Peters et al. ${ }^{18}$ On the exterior boundary of the spherical shell, the fluid-structure interaction needs to be considered because the light structure is immersed in heavy fluid, where the fluid is water. 


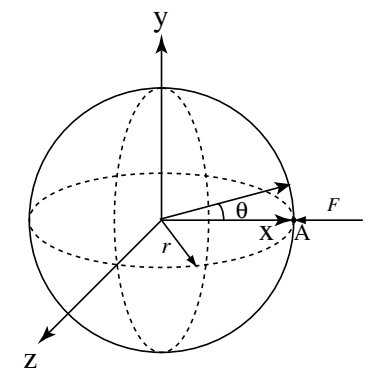

Fig. 1. Spherical shell excited by a single force at point $A$.

Table 1. Material and geometric data for a submerged spherical shell.

\begin{tabular}{lccc}
\hline Density (water) & $\rho$ & 1000 & $\mathrm{~kg} / \mathrm{m}^{3}$ \\
Speed of sound & $c$ & 1482 & $\mathrm{~m} / \mathrm{s}$ \\
Density (steel) & $\rho_{s}$ & 7860 & $\mathrm{~kg} / \mathrm{m}^{3}$ \\
Young's modulus & $E$ & 210 & $\mathrm{GPa}$ \\
Poisson' ratio & $\nu$ & 0.3 & \\
Radius of sphere & $r$ & 5 & $\mathrm{~m}$ \\
Thickness of shell & $h$ & 0.05 & $\mathrm{~m}$ \\
\hline
\end{tabular}

The interior of the shell is full of air, so the fluid-structure interaction is ignored. An analytical solution is available from Junger and Feit ${ }^{42}$ with the sound pressure $p(\theta)$ and the displacement $u(\theta)$ at the surface of the sphere, respectively, as

$$
p(\theta)=\frac{F}{4 \pi r^{2}} \sum_{n=0}^{\infty} \frac{(2 n+1) z_{n}}{Z_{n}+z_{n}} P_{n}(\cos \theta)
$$

and

$$
u(\theta)=-\frac{F}{4 \pi r^{2} i \omega} \sum_{n=0}^{\infty} \frac{2 n+1}{Z_{n}+z_{n}} P_{n}(\cos \theta) .
$$

$P_{n}$ are the coefficients of the Legendre polynomials of order $n$. The radiation impedance $z_{n}$ and the modal impedance of shell $Z_{n}$ can be obtained in Ref. 42. Given the axisymmetry along the $\mathbf{x}$-axis, the radiated sound power is written as follows:

$$
\begin{aligned}
P & =\pi r^{2} \int_{0}^{\pi} \Re\left\{p(\theta) v_{f}^{*}(\theta)\right\} \sin (\theta) d \theta \\
& \approx \frac{\pi^{2} r^{2}}{n} \sum_{m=1}^{n} \Re\left\{p\left(\theta_{m}\right) v_{f}^{*}\left(\theta_{m}\right)\right\} \sin \left(\theta_{m}\right)
\end{aligned}
$$

with $\theta_{m}=m \pi / n, v_{f}^{*}\left(\theta_{m}\right)=i \omega u^{*}\left(\theta_{m}\right)$, and a sufficiently large $n$.

The FE model of the structure is created in ANSYS, ${ }^{43}$ which is meshed using shell elements SHELL63. An approximate element length of $0.35 \mathrm{~m}$ leads to a mesh of 5960 
triangular shell elements. The BE surface mesh coincides with the FE mesh. Constant BEs are used for this analysis. Radiated sound power is evaluated based on the displacement and sound pressure on the wet surface of the structure.

A $0.2 \mathrm{~Hz}$ to $100 \mathrm{~Hz}$ step size is used to evaluate the analytical solution. The FE/FMBE solution is evaluated in $1 \mathrm{~Hz}$ steps. Additional solutions are inserted into the vicinity of the resonant peaks. The maximum number of BEs per leaf is set to 20 when the FM algorithm is used. The number of generated tree levels is 5, and a GMRES residual below $10^{-4}$ is demanded. A lower order residual has been tested which does not improve the results in the cases presented herein.

Figures 2 and 3 respectively present the analytical and FE/FMBE solutions to sound pressure and displacement at point $\theta=\pi$. Figure 4 shows the analytical and FE/FMBE solutions to radiated sound power. The numerical solution clearly agrees with the analytical one, which indicates the validity of the solution algorithm and its correct implementation.

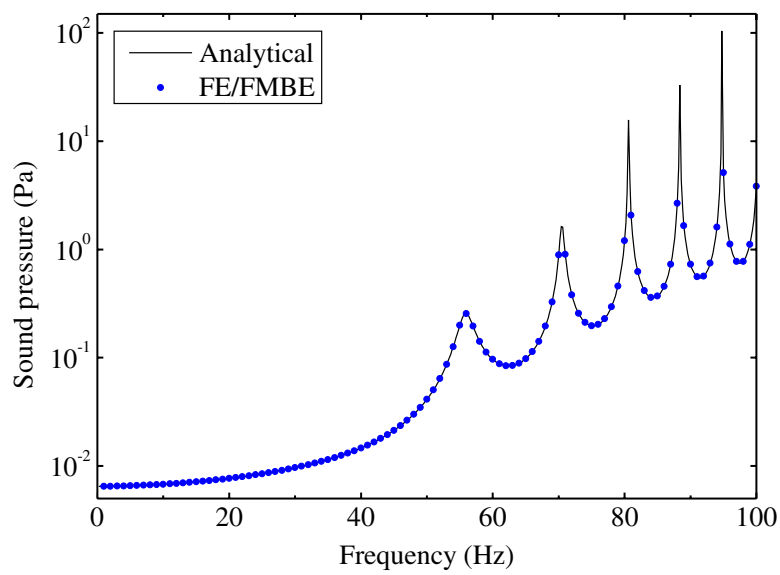

Fig. 2. Sound pressure on sphere at $\theta=\pi$.

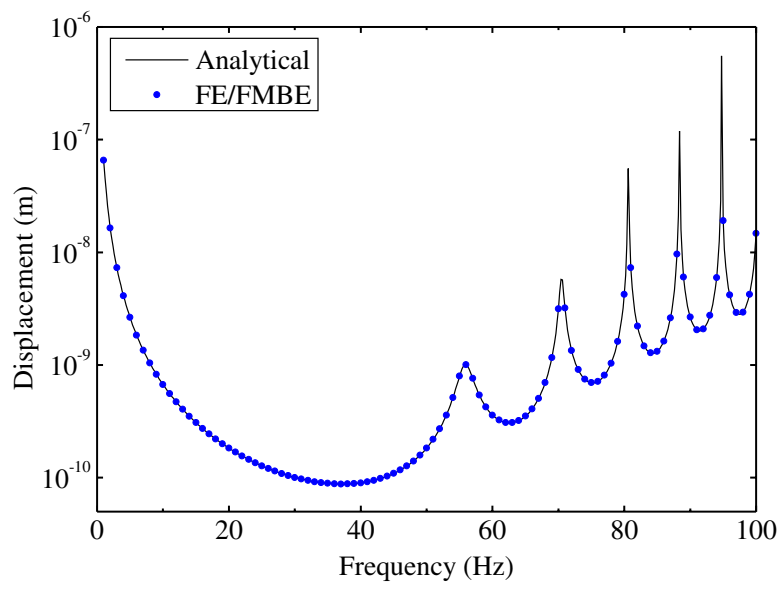

Fig. 3. Displacement on sphere at $\theta=\pi$. 
L. Chen et al.

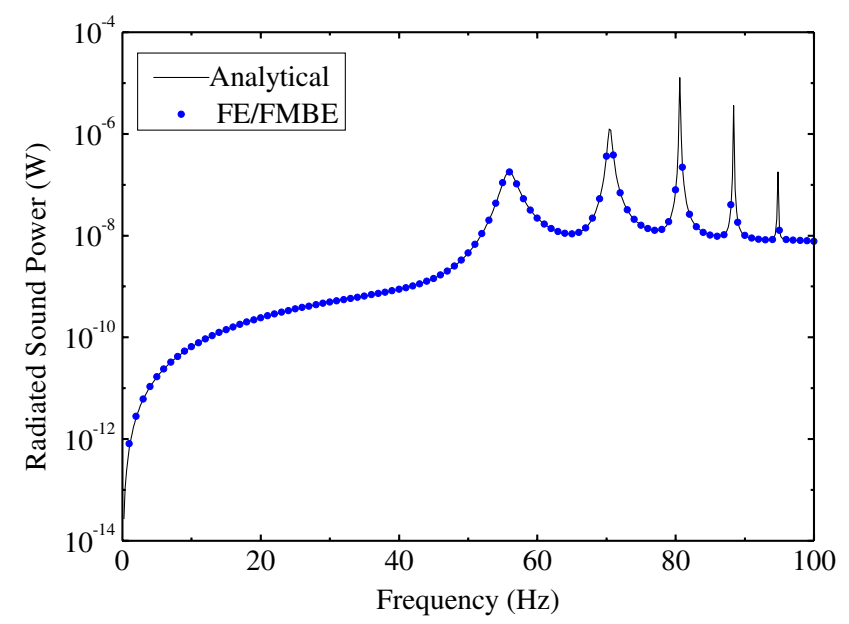

Fig. 4. Radiated sound power.

\subsection{Sound power sensitivity}

The sensitivity of the radiated sound power is determined using Eq. (19). A number of model parameters are investigated to validate the method proposed in the preceding sections. These parameters are as follows:

(1) fluid density $\rho$,

(2) structural entities density $\rho_{s}$, Young's modulus $E$, Poisson's ratio $\nu$, shell thickness $h$, and

(3) radius $r$ as a geometric quantity.

Fluid density $\rho$ accounts for the design variable in the first case. The derivatives $\frac{\partial \mathbf{A}}{\partial \rho}, \frac{\partial \mathbf{C}_{s f}}{\partial \rho}$ and $\frac{\partial \mathbf{H}}{\partial \rho}$ in Eq. (16) disappear because $\mathbf{A}, \mathbf{C}_{s f}$ and $\mathbf{H}$ are independent of $\rho$. Furthermore, $\mathbf{f}_{s}$ and $\mathbf{p}_{i}$ are independent of the chosen design variable. Therefore, their sensitivities vanish too. Thus, vector $\mathbf{r}$ in Eq. (15) takes the following form

$$
\mathbf{r}=\left[\begin{array}{c}
\mathbf{0} \\
\frac{\partial\left(\mathbf{G S}^{-1} \mathbf{C}_{f s}\right)}{\partial \rho} \mathbf{u}
\end{array}\right]=\left[\begin{array}{c}
\mathbf{0} \\
\overline{\mathbf{G}} \mathbf{S}^{-1} \mathbf{C}_{f s} \mathbf{u}
\end{array}\right] .
$$

Obviously, $\frac{\partial \mathbf{C}_{f s}}{\partial \rho}=0$ and $\frac{\partial \mathbf{S}}{\partial \rho}=0$. Only $\mathbf{G}$ depends on fluid density. The situation in this case is simple because matrix $\mathbf{G}$ is explicitly dependent on fluid density such that $\mathbf{G}=\rho \overline{\mathbf{G}}$ with $\overline{\mathbf{G}}$ being independent of fluid density $\rho$. Sound power sensitivity with respect to fluid density is finally obtained by solving Eq. (19). This sensitivity can be understood as an analytical sensitivity. Hence, the sensitivity solution has a similar numerical error as the sound power solution itself. No additional error stems from the finite difference approximations of the derivatives. 


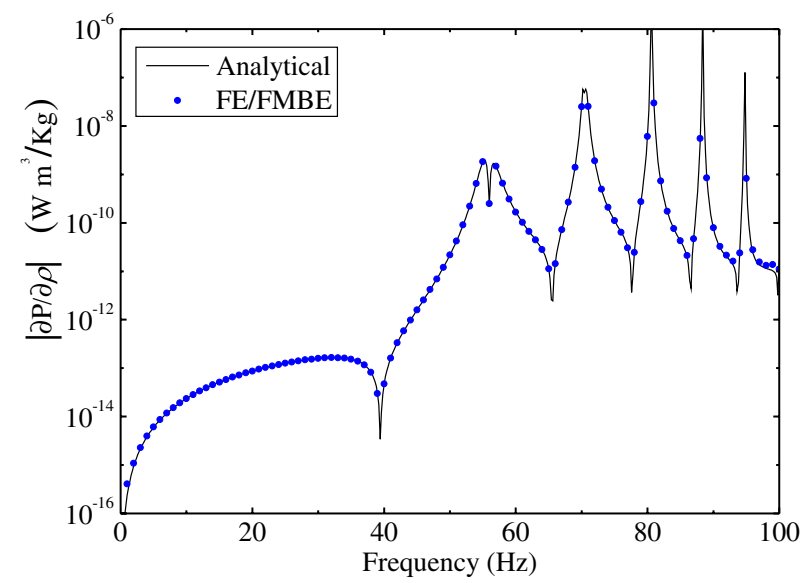

Fig. 5. Sound power sensitivity (magnitude) with respect to fluid density.

Figure 5 presents sound power sensitivity with respect to fluid density. While sound power remains insensitive in the low frequency range, sensitivity increases within the vicinity of the resonance peaks. The numerical solution agrees well with the analytical solution.

The second case considers structural design variables such as structural material data $\rho_{s}, E, \nu$, and shell thickness $h$. All entries in $\partial \mathbf{B} / \partial \vartheta$ then disappear in Eq. (16) except $\frac{\partial \mathbf{A}}{\partial \vartheta} \neq 0 . \mathbf{f}_{s}$ and $\mathbf{p}_{i}$ are again independent of structural-design variables. Hence, vector $\mathbf{r}$ in Eq. (15) results in

$$
\mathbf{r}=\left[\begin{array}{c}
-\frac{\partial \mathbf{A}}{\partial \vartheta} \mathbf{u} \\
\mathbf{0}
\end{array}\right]
$$

The most accurate method in determining $\partial \mathbf{A} / \partial \vartheta$ is to use an analytical scheme. However, this method requires access to the shell element formulation, which can be challenging when a commercial tool such as ANSYS is used. Therefore, the authors have decided to use forward finite difference schemes applied to the dynamic stiffness matrix provided by ANSYS. This approach is known as a semi-analytical sensitivity analysis,,${ }^{1,5,6}$ where all entries of $\partial \mathbf{A} / \partial \vartheta$ are approximated by a forward finite difference scheme. The step size $\Delta \vartheta$ used for perturbation depends on the parameter and is defined by normalized factor $\alpha=\Delta \vartheta / \vartheta$. Although initial trials started with $\alpha=10^{-5}$, this step size has been found to be too small except for the structural density $\rho_{s} . \alpha=0.01$ is applied to sensitivities with respect to Poisson's ratio $\nu$ and Young's modulus $E$, whereas $\alpha=0.02$ is used for shell thickness $h$.

Figures 6 and 7 present the sensitivity of the radiated sound power with respect to structural density and shell thickness, respectively. Very similar to fluid density, the sound power sensitivity with respect to structural density and shell thickness is small in the low frequency range and exhibit peaks within the vicinity of the resonances. Again, the numerical and analytical solutions agree well with each other. 


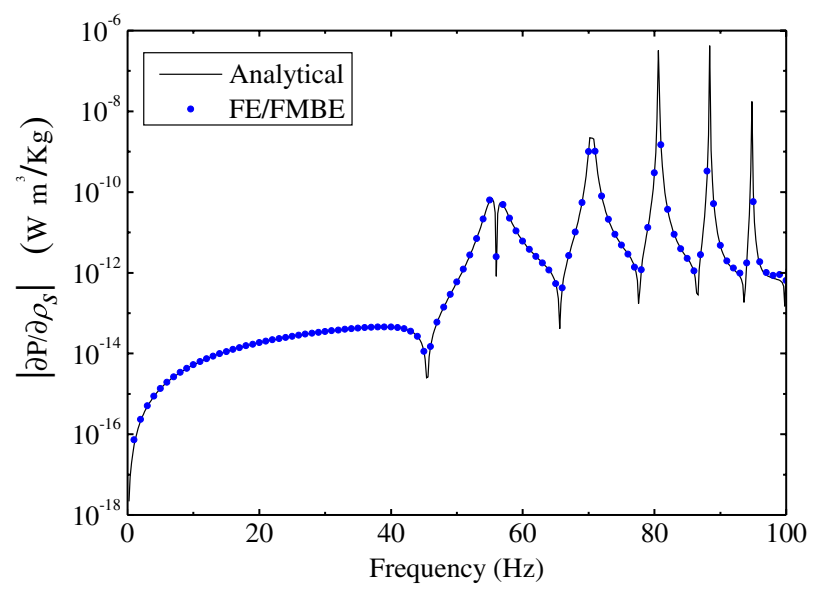

Fig. 6. Sound power sensitivity (magnitude) with respect to structural density $\rho_{s}$.

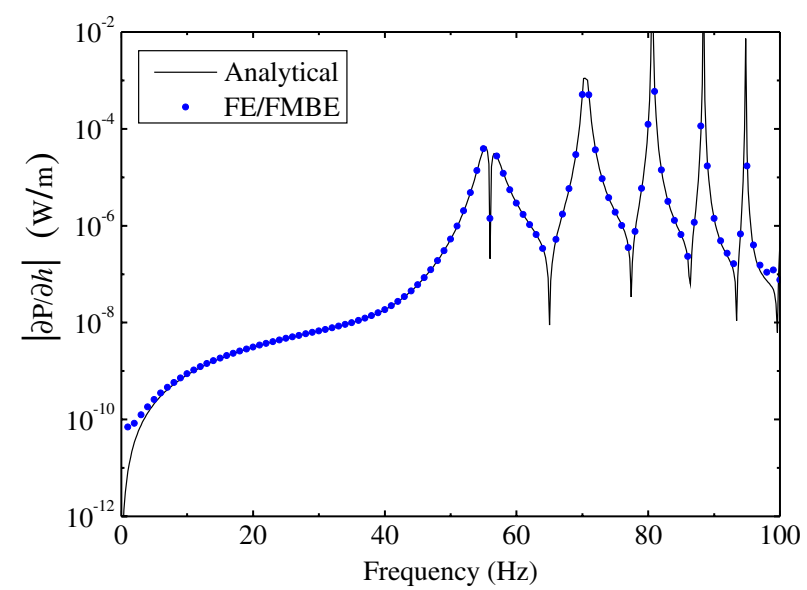

Fig. 7. Sound power sensitivity (magnitude) with respect to shell thickness $h$.

The third category of design parameters has an effect on model geometry. The spherical shell in this case allows the variation of only one parameter. This variable is the radius of the sphere $r$. Since the geometry of the wet surface of the structure depends on $r$, all entries of matrix B in Eq. (16) must be computed. Again, semi-analytical sensitivity analysis is applied to system matrices $\mathbf{A}$ and $\mathbf{H}$, coupling matrix $\mathbf{C}_{s f}$ and product $\mathbf{G} \mathbf{S}^{-1} \mathbf{C}_{f s}$. Similar to previous cases, $\mathbf{f}_{s}$ and $\mathbf{p}_{i}$ are independent of $r$. The column matrix $\mathbf{r}$ in Eq. (15) now takes the following form:

$$
\mathbf{r}=\left[\begin{array}{c}
-\frac{\partial \mathbf{A}}{\partial r} \mathbf{u}+\frac{\partial \mathbf{C}_{s f}}{\partial r} \mathbf{p} \\
\frac{\partial\left(\mathbf{G S}^{-1} \mathbf{C}_{f s}\right)}{\partial r} \mathbf{u}-\frac{\partial \mathbf{H}}{\partial r} \mathbf{p}
\end{array}\right]
$$


In addition to the more complex $\mathbf{r}$ and different from the first two categories of parameters, the second term on the right side of Eq. (19) does not disappear because $\mathbf{C}_{f s}=\mathbf{C}_{f s}(r)$. Similar to the derivatives of $\mathbf{A}$, a semi-analytical approach based on the finite differences of the coupling matrix $\mathbf{C}_{f s}$ is applied to compute the second term on the right side of Eq. (19).

Figure 8 presents sound power sensitivity with respect to radius of the sphere. Qualitatively, the solution appears similar to those of other sensitivities. Again, the analytical and numerical solutions match well.

However, an important difference from other sensitivity evaluations has been found.

The optimal step size of the finite difference scheme for evaluating the derivatives in Eq. (29) has been obtained in this example. After numerous tests, factor $\alpha=\Delta \vartheta / \vartheta$ with $\vartheta=r$ has been chosen in terms of frequency $f$ as follows:

- $\alpha=0.008$ for $0 \mathrm{~Hz}<f \leq 40 \mathrm{~Hz}$,

- $\alpha=0.002$ for $40 \mathrm{~Hz}<f \leq 70 \mathrm{~Hz}$ and

- $\alpha=0.001$ for $70 \mathrm{~Hz}<f \leq 100 \mathrm{~Hz}$.

Using three different values for $\alpha$ within the frequency range of up to $100 \mathrm{~Hz}$ is necessary. This procedure maintains overall sensitivity error below $10 \%$.

Table 2 presents sound power sensitivity values with respect to different design variables and the comparison between FE/FMBE calculation and the analytical value. The numerically evaluated sensitivities are extremely close to the analytical ones, which is confirmed when the relative error between them is checked. An error function is subsequently introduced for this situation. This error function is defined as ERROR = $\left(P_{\text {num }}^{\prime}-P_{\text {an }}^{\prime}\right) / P_{\text {an }}^{\prime} \times 100 \%$, where $P_{\text {num }}^{\prime}$ is the result for sound power sensitivity using the FE/FMBE algorithm and $P_{\text {an }}^{\prime}$ is the result of sound power sensitivity using the analytical representation of the radiated sound power. The errors of the numerical solution are listed in Table 3. Basically, the error confirms the expectation that it goes up with frequency and it increases in the vicinity of resonances.

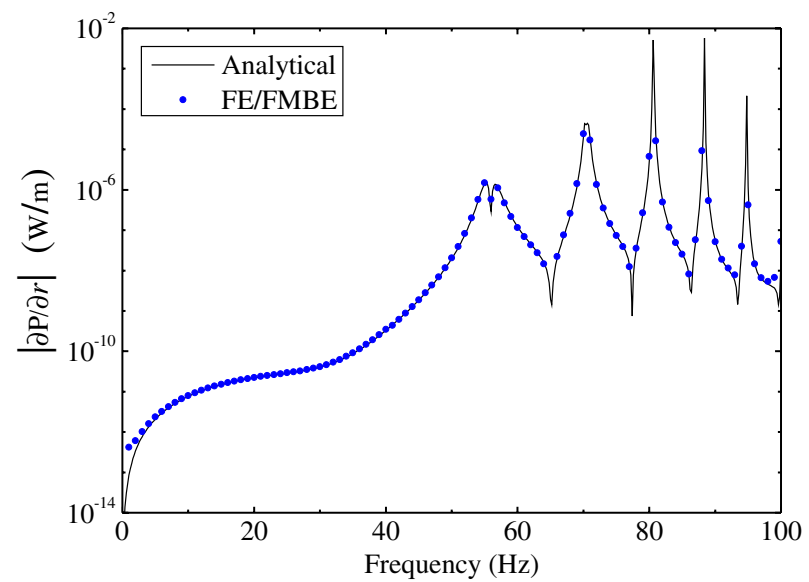

Fig. 8. Sound power sensitivity (magnitude) with respect to radius $r$ of the sphere. 
Table 2. Sensitivities of radiated sound power with respect to different design variables.

\begin{tabular}{|c|c|c|c|c|c|c|c|}
\hline $\begin{array}{c}f \\
{[\mathrm{~Hz}]}\end{array}$ & Method & $\begin{array}{c}\partial P / \partial \rho \\
{\left[(\mathrm{m} / \mathrm{s})^{2}\right]}\end{array}$ & $\begin{array}{l}\partial P / \partial \rho_{s} \\
{\left[(\mathrm{~m} / \mathrm{s})^{2}\right]}\end{array}$ & $\begin{array}{c}\partial P / \partial v \\
{[\mathrm{~Pa}]}\end{array}$ & $\partial P / \partial E$ & $\begin{array}{l}\partial P / \partial h \\
{[\mathrm{~Pa} / \mathrm{m}]}\end{array}$ & $\begin{array}{l}\partial P / \partial r \\
{[\mathrm{~Pa} / \mathrm{m}]}\end{array}$ \\
\hline 10 & $\begin{array}{c}\mathrm{FE} / \mathrm{FMBE} \\
\text { analytical }\end{array}$ & $\begin{array}{l}-2.36 \mathrm{E}-14 \\
-2.35 \mathrm{E}-14\end{array}$ & $\begin{array}{l}-5.23 \mathrm{E}-15 \\
-5.22 \mathrm{E}-15\end{array}$ & $\begin{array}{l}-2.03 \mathrm{E}-12 \\
-7.35 \mathrm{E}-13\end{array}$ & $\begin{array}{l}-5.45 \mathrm{E}-24 \\
-2.45 \mathrm{E}-24\end{array}$ & $\begin{array}{l}-8.74 \mathrm{E}-10 \\
-8.30 \mathrm{E}-10\end{array}$ & $\begin{array}{l}7.92 \mathrm{E}-12 \\
7.63 \mathrm{E}-12\end{array}$ \\
\hline 20 & $\begin{array}{c}\mathrm{FE} / \mathrm{FMBE} \\
\text { analytical }\end{array}$ & $\begin{array}{l}-8.71 \mathrm{E}-14 \\
-8.73 \mathrm{E}-14\end{array}$ & $\begin{array}{l}-1.85 \mathrm{E}-14 \\
-1.85 \mathrm{E}-14\end{array}$ & $\begin{array}{l}-1.34 \mathrm{E}-11 \\
-1.21 \mathrm{E}-11\end{array}$ & $\begin{array}{l}-4.47 \mathrm{E}-23 \\
-4.22 \mathrm{E}-23\end{array}$ & $\begin{array}{l}-3.13 \mathrm{E}-09 \\
-3.09 \mathrm{E}-09\end{array}$ & $\begin{array}{l}2.24 \mathrm{E}-11 \\
2.20 \mathrm{E}-11\end{array}$ \\
\hline 30 & $\begin{array}{c}\mathrm{FE} / \mathrm{FMBE} \\
\text { analytical }\end{array}$ & $\begin{array}{l}-1.58 \mathrm{E}-13 \\
-1.59 \mathrm{E}-13\end{array}$ & $\begin{array}{l}-3.49 \mathrm{E}-14 \\
-3.49 \mathrm{E}-14\end{array}$ & $\begin{array}{l}-6.24 \mathrm{E}-11 \\
-5.92 \mathrm{E}-11\end{array}$ & $\begin{array}{l}-2.87 \mathrm{E}-22 \\
-2.85 \mathrm{E}-22\end{array}$ & $\begin{array}{l}-6.72 \mathrm{E}-09 \\
-6.68 \mathrm{E}-09\end{array}$ & $\begin{array}{l}4.16 \mathrm{E}-11 \\
4.04 \mathrm{E}-11\end{array}$ \\
\hline 40 & $\begin{array}{c}\mathrm{FE} / \mathrm{FMBE} \\
\text { analytical }\end{array}$ & $\begin{array}{l}4.73 \mathrm{E}-14 \\
4.63 \mathrm{E}-14\end{array}$ & $\begin{array}{l}-4.51 \mathrm{E}-14 \\
-4.51 \mathrm{E}-14\end{array}$ & $\begin{array}{l}-1.14 \mathrm{E}-10 \\
-9.65 \mathrm{E}-11\end{array}$ & $\begin{array}{l}-2.71 \mathrm{E}-21 \\
-2.71 \mathrm{E}-21\end{array}$ & $\begin{array}{l}-1.85 \mathrm{E}-08 \\
-1.84 \mathrm{E}-08\end{array}$ & $\begin{array}{l}3.48 \mathrm{E}-10 \\
3.28 \mathrm{E}-10\end{array}$ \\
\hline 50 & $\begin{array}{c}\text { FE/FMBE } \\
\text { analytical }\end{array}$ & $\begin{array}{l}2.17 \mathrm{E}-11 \\
2.17 \mathrm{E}-11\end{array}$ & & & $\begin{array}{l}-1.47 \mathrm{E}-19 \\
-1.46 \mathrm{E}-19\end{array}$ & $\begin{array}{l}-5.25 \mathrm{E}-07 \\
-5.18 \mathrm{E}-07\end{array}$ & $\begin{array}{l}2.05 \mathrm{E}-08 \\
1.96 \mathrm{E}-08\end{array}$ \\
\hline 55 & $\begin{array}{c}\text { FE/FMBE } \\
\text { analytical }\end{array}$ & $\begin{array}{l}6.47 \mathrm{E}-10 \\
6.47 \mathrm{E}-10\end{array}$ & $\begin{array}{l}6.29 \mathrm{E}-11 \\
6.25 \mathrm{E}-11\end{array}$ & $\begin{array}{l}5.95 \mathrm{E}-07 \\
6.06 \mathrm{E}-07\end{array}$ & $\begin{array}{l}-1.16 \mathrm{E}-17 \\
-1.15 \mathrm{E}-17\end{array}$ & $\begin{array}{l}-3.88 \mathrm{E}-05 \\
-3.80 \mathrm{E}-05\end{array}$ & $\begin{array}{l}1.48 \mathrm{E}-06 \\
1.42 \mathrm{E}-06\end{array}$ \\
\hline 60 & $\begin{array}{c}\mathrm{FE} / \mathrm{FMBE} \\
\text { analytical }\end{array}$ & $\begin{array}{l}-1.67 \mathrm{E}-10 \\
-1.68 \mathrm{E}-10\end{array}$ & $\begin{array}{l}-6.05 \mathrm{E}-12 \\
-6.11 \mathrm{E}-12\end{array}$ & $\begin{array}{l}-5.05 \mathrm{E}-08 \\
-5.22 \mathrm{E}-08\end{array}$ & $\begin{array}{l}9.17 \mathrm{E}-19 \\
9.26 \mathrm{E}-19\end{array}$ & $\begin{array}{l}2.90 \mathrm{E}-06 \\
2.96 \mathrm{E}-06\end{array}$ & $\begin{array}{l}-1.16 \mathrm{E}-07 \\
-1.22 \mathrm{E}-07\end{array}$ \\
\hline 65 & $\begin{array}{c}\mathrm{FE} / \mathrm{FMBE} \\
\text { analytical }\end{array}$ & $\begin{array}{l}-1.12 \mathrm{E}-11 \\
-1.11 \mathrm{E}-11\end{array}$ & $\begin{array}{l}-5.41 \mathrm{E}-13 \\
-5.46 \mathrm{E}-13\end{array}$ & $\begin{array}{l}-6.27 \mathrm{E}-09 \\
-6.32 \mathrm{E}-09\end{array}$ & & $\begin{array}{l}6.89 \mathrm{E}-09 \\
1.62 \mathrm{E}-08\end{array}$ & $\begin{array}{l}-5.96 \mathrm{E}-10 \\
-1.92 \mathrm{E}-09\end{array}$ \\
\hline 70 & $\begin{array}{c}\mathrm{FE} / \mathrm{FMBE} \\
\text { analytical }\end{array}$ & $\begin{array}{l}2.51 \mathrm{E}-08 \\
2.68 \mathrm{E}-08\end{array}$ & & & $\begin{array}{l}-1.59 \mathrm{E}-16 \\
-1.61 \mathrm{E}-16\end{array}$ & $\begin{array}{l}-5.10 \mathrm{E}-04 \\
-4.74 \mathrm{E}-04\end{array}$ & $\begin{array}{l}2.46 \mathrm{E}-05 \\
2.06 \mathrm{E}-05\end{array}$ \\
\hline 75 & $\begin{array}{c}\mathrm{FE} / \mathrm{FMBE} \\
\text { analytical }\end{array}$ & $\begin{array}{l}-1.11 \mathrm{E}-10 \\
-1.10 \mathrm{E}-10\end{array}$ & $\begin{array}{l}-4.85 \mathrm{E}-12 \\
-4.88 \mathrm{E}-12\end{array}$ & $\begin{array}{l}-2.02 \mathrm{E}-08 \\
-2.13 \mathrm{E}-08\end{array}$ & $\begin{array}{l}6.33 \mathrm{E}-19 \\
6.36 \mathrm{E}-19\end{array}$ & $\begin{array}{l}1.90 \mathrm{E}-06 \\
1.94 \mathrm{E}-06\end{array}$ & $\begin{array}{l}-7.34 \mathrm{E}-08 \\
-7.52 \mathrm{E}-08\end{array}$ \\
\hline 80 & $\begin{array}{c}\mathrm{FE} / \mathrm{FMBE} \\
\text { analytical }\end{array}$ & $\begin{array}{l}6.04 \mathrm{E}-09 \\
6.36 \mathrm{E}-09\end{array}$ & $\begin{array}{l}2.96 \mathrm{E}-10 \\
2.94 \mathrm{E}-10\end{array}$ & $\begin{array}{l}6.33 \mathrm{E}-07 \\
6.86 \mathrm{E}-07\end{array}$ & $\begin{array}{l}-4.02 \mathrm{E}-17 \\
-3.95 \mathrm{E}-17\end{array}$ & $\begin{array}{l}-1.23 \mathrm{E}-04 \\
-1.08 \mathrm{E}-04\end{array}$ & $\begin{array}{l}6.69 \mathrm{E}-06 \\
4.92 \mathrm{E}-06\end{array}$ \\
\hline 85 & $\begin{array}{c}\mathrm{FE} / \mathrm{FMBE} \\
\text { analytical }\end{array}$ & $\begin{array}{l}-4.27 \mathrm{E}-11 \\
-4.21 \mathrm{E}-11\end{array}$ & $\begin{array}{l}-2.25 \mathrm{E}-12 \\
-2.24 \mathrm{E}-12\end{array}$ & $\begin{array}{l}-6.87 \mathrm{E}-09 \\
-7.40 \mathrm{E}-09\end{array}$ & $\begin{array}{l}2.39 \mathrm{E}-19 \\
2.37 \mathrm{E}-19\end{array}$ & $\begin{array}{l}6.55 \mathrm{E}-07 \\
6.57 \mathrm{E}-07\end{array}$ & $\begin{array}{l}-2.52 \mathrm{E}-08 \\
-2.55 \mathrm{E}-08\end{array}$ \\
\hline 90 & $\begin{array}{l}\text { FE/FMBE } \\
\text { analytical }\end{array}$ & $\begin{array}{l}-7.91 \mathrm{E}-11 \\
-7.75 \mathrm{E}-11\end{array}$ & $\begin{array}{l}-4.75 \mathrm{E}-12 \\
-4.75 \mathrm{E}-12\end{array}$ & $\begin{array}{l}-8.02 \mathrm{E}-09 \\
-9.06 \mathrm{E}-09\end{array}$ & $\begin{array}{l}5.07 \mathrm{E}-19 \\
5.08 \mathrm{E}-19\end{array}$ & $\begin{array}{l}1.41 \mathrm{E}-06 \\
1.48 \mathrm{E}-06\end{array}$ & $\begin{array}{l}-5.12 \mathrm{E}-08 \\
-5.62 \mathrm{E}-08\end{array}$ \\
\hline 95 & $\begin{array}{c}\mathrm{FE} / \mathrm{FMBE} \\
\text { analytical }\end{array}$ & $\begin{array}{l}-8.27 \mathrm{E}-10 \\
-1.24 \mathrm{E}-09\end{array}$ & $\begin{array}{l}-5.71 \mathrm{E}-11 \\
-1.00 \mathrm{E}-10\end{array}$ & $\begin{array}{l}-4.06 \mathrm{E}-08 \\
-8.23 \mathrm{E}-08\end{array}$ & $\begin{array}{l}6.01 \mathrm{E}-18 \\
1.08 \mathrm{E}-17\end{array}$ & $\begin{array}{l}1.70 \mathrm{E}-05 \\
4.77 \mathrm{E}-05\end{array}$ & $\begin{array}{l}-4.25 \mathrm{E}-07 \\
-1.21 \mathrm{E}-06\end{array}$ \\
\hline 100 & $\begin{array}{c}\mathrm{FE} / \mathrm{FMBE} \\
\text { analytical }\end{array}$ & $\begin{array}{r}-1.10 \mathrm{E}-11 \\
1.73 \mathrm{E}-11\end{array}$ & $\begin{array}{r}-6.39 \mathrm{E}-13 \\
1.26 \mathrm{E}-12\end{array}$ & $\begin{array}{l}-1.40 \mathrm{E}-09 \\
-2.16 \mathrm{E}-09\end{array}$ & $\begin{array}{r}4.05 \mathrm{E}-20 \\
-1.50 \mathrm{E}-19\end{array}$ & $\begin{array}{r}7.58 \mathrm{E}-08 \\
-3.71 \mathrm{E}-07\end{array}$ & $\begin{array}{l}5.23 \mathrm{E}-08 \\
1.84 \mathrm{E}-08\end{array}$ \\
\hline
\end{tabular}

As clearly visible in the previous figures, five resonances are found within the frequency range of up to $100 \mathrm{~Hz}$. The resonance frequencies are determined as 55.9, 70.5, 80.6, 88.4 and 94.8 Hz. As shown in Figs. 5-8 and in Table 2, the sensitivities are increasing close to the resonances. With some exceptions, the error remains below $10 \%$ which is quite acceptable for this kind of analysis. However, the sensitivity results exhibit significant differences in order of magnitude because variables have different orders of magnitude themselves. Therefore, normalizing these sensitivities is regarded of useful. The derivative is multiplied by the parameter and divided by the sound power value as follows:

$$
\bar{P}_{, \vartheta}=\frac{\vartheta}{P(\vartheta)} \frac{\partial P}{\partial \vartheta}
$$


Table 3. Relative errors of the sensitivities of radiated sound power (\%).

\begin{tabular}{crrrrrr}
\hline$f$ in $[\mathrm{Hz}]$ & $\partial P / \partial \rho$ & $\partial P / \partial \rho_{s}$ & $\partial P / \partial v$ & $\partial P / \partial E$ & $\partial P / \partial h$ & $\partial P / \partial r$ \\
\hline 10 & 0.243 & 0.226 & 177 & 122 & 5.28 & 3.87 \\
20 & -0.176 & 0.0253 & 10.9 & 5.99 & 1.28 & 1.93 \\
30 & -0.330 & 0.00219 & 5.43 & 0.79 & 0.591 & 2.94 \\
40 & 1.99 & 0.0136 & 18.5 & 0.101 & 0.475 & 6.06 \\
50 & -0.123 & 0.304 & -2.48 & 0.264 & 1.31 & 4.37 \\
55 & -0.154 & 0.506 & -1.86 & 0.531 & 2.20 & 4.64 \\
60 & -0.318 & -0.954 & -3.28 & -1.04 & -1.96 & -4.97 \\
65 & 0.711 & -0.904 & -0.741 & -3.08 & -57.3 & -68.8 \\
70 & -6.39 & -2.09 & -7.16 & -1.66 & 7.54 & 19.4 \\
75 & 0.376 & -0.547 & -5.20 & -0.548 & -1.92 & -2.38 \\
80 & -5.18 & 0.968 & -7.76 & 1.66 & 14.6 & 35.9 \\
85 & 1.55 & 0.428 & -7.17 & 1.01 & -0.276 & -0.915 \\
90 & 2.03 & 0.0601 & -11.4 & -0.326 & -5.04 & -8.80 \\
95 & -33.1 & -42.9 & -50.7 & -44.6 & -64.4 & -64.9 \\
100 & -164 & -151 & -35.6 & -127 & -120 & 185 \\
\hline
\end{tabular}

Table 4 displays the normalized sensitivities of radiated sound power. With the exception of $65 \mathrm{~Hz}$, the Poisson's ratio is easily determined as the most insensitive among the six parameters investigated. At approximately $65 \mathrm{~Hz}$, sound power sensitivity with respect to shell thickness changes its algebraic sign from positive to negative. Therefore, sensitivity accidently acquires a small value at this point. Slightly more variety is observed when searching for the most sensitive parameter, which is shell thickness in the very low frequency range. From $40 \mathrm{~Hz}$ on and with the exception of $65 \mathrm{~Hz}$, the radius exhibits the highest sensitivity. Similarly to shell thickness, radius sensitivity also changes its algebraic signs within the vicinity of $65 \mathrm{~Hz}$. Therefore, fluid density is the most sensitive parameter at this frequency.

It is further interesting to recognize that the algebraic signs are the same for the sensitivities of the fluid and structural density. The exception at $40 \mathrm{~Hz}$ is attributed to a change in algebraic signs within the vicinity of this frequency. Sensitivities with respect to structural density and Poisson's ratio have the same algebraic signs up to $95 \mathrm{~Hz}$. A similar correlation with the exception of low frequencies (i.e. up to $40 \mathrm{~Hz}$ ) is observed for these two parameters and sphere radius. Sphere radius exhibits a strong correlation with Young's modulus and shell thickness to the extent that the algebraic signs of radius' sensitivities are opposite to those of sensitivities with respect to Young's modulus and shell thickness. Apparently, three frequency ranges must be considered. The first range is the low frequency range of up to somewhere between $40 \mathrm{~Hz}$ and $50 \mathrm{~Hz}$, which is most likely related to the first resonance. ${ }^{1}$ The second frequency range covers the remaining values with the exception of the highest frequency of $100 \mathrm{~Hz}$.

The effect of resonances is clearly recognized even among the normalized sensitivities because their values increase in this region. This result is not surprising because the sensitivity evaluation in Eq. (19) is based on the inversion of the same system matrix $\mathbf{B}$ as the 
Table 4. Normalized sensitivities of radiated sound power with respect to different design variables.

\begin{tabular}{|c|c|c|c|c|c|c|c|}
\hline$f$ in $[\mathrm{Hz}]$ & Method & $\bar{P}_{, \rho}$ & $\bar{P}_{, \rho_{s}}$ & $\bar{P}_{, \nu}$ & $\bar{P}_{, E}$ & $\bar{P}_{, h}$ & $\bar{P}_{, r}$ \\
\hline \multirow[t]{2}{*}{10} & FE/FMBE & $-3.62 \mathrm{E}-1$ & $-6.32 \mathrm{E}-1$ & $-9.36 \mathrm{E}-3$ & $-1.76 \mathrm{E}-2$ & $-6.71 \mathrm{E}-1$ & $\begin{array}{l}6.08 \mathrm{E}-1 \\
5.86 \mathrm{E}-1\end{array}$ \\
\hline & $\begin{array}{l}\text { analytical } \\
\text { FE/FMBE }\end{array}$ & $\begin{array}{l}-3.61 \mathrm{E}-1 \\
-3.61 \mathrm{E}-1\end{array}$ & $\begin{array}{l}-6.31 \mathrm{E}-1 \\
-6.03 \mathrm{E}-1\end{array}$ & $\begin{array}{l}-3.39 \mathrm{E}-3 \\
-1.66 \mathrm{E}-2\end{array}$ & $\begin{array}{l}-7.92 \mathrm{E}-3 \\
-3.89 \mathrm{E}-2\end{array}$ & $\begin{array}{l}-6.38 \mathrm{E}-1 \\
-6.47 \mathrm{E}-1\end{array}$ & $\begin{array}{l}5.86 \mathrm{E}-1 \\
4.64 \mathrm{E}-1\end{array}$ \\
\hline 20 & & $-3.61 \mathrm{E}-1$ & $-6.02 \mathrm{E}-1$ & $-1.50 \mathrm{E}-2$ & $-3.67 \mathrm{E}-2$ & $-6.38 \mathrm{E}-1$ & $4.54 \mathrm{E}-1$ \\
\hline \multirow[t]{2}{*}{30} & FE/FMBE & $-3.21 \mathrm{E}-1$ & $-5.57 \mathrm{E}-1$ & $-3.80 \mathrm{E}-2$ & $-1.22 \mathrm{E}-1$ & $-6.81 \mathrm{E}-1$ & $4.22 \mathrm{E}-1$ \\
\hline & analytical & $-3.22 \mathrm{E}-1$ & $-5.56 \mathrm{E}-1$ & $-3.60 \mathrm{E}-2$ & $-1.21 \mathrm{E}-1$ & $-6.77 \mathrm{E}-1$ & $4.09 \mathrm{E}-1$ \\
\hline \multirow[t]{2}{*}{40} & FE/FMBE & $5.39 \mathrm{E}-2$ & $-4.04 \mathrm{E}-1$ & $-3.91 \mathrm{E}-2$ & $-6.49 \mathrm{E}-1$ & $-1.06 \mathrm{E} 00$ & $1.98 \mathrm{E} 00$ \\
\hline & ical & $5.28 \mathrm{E}-2$ & $-4.04 \mathrm{E}-1$ & $-3.30 \mathrm{E}-2$ & $-6.48 \mathrm{E}-1$ & $-1.05 \mathrm{E} 00$ & $1.87 \mathrm{E} 00$ \\
\hline \multirow[t]{2}{*}{50} & FE/FMBE & $4.76 \mathrm{E} 00$ & $1.01 \mathrm{E} 00$ & $4.41 \mathrm{E}-1$ & $-6.77 \mathrm{E} 00$ & $-5.76 \mathrm{E} 00$ & $2.25 \mathrm{E}+1$ \\
\hline & & 4.77E00 & $1.01 \mathrm{~F}$ & $4.53 \mathrm{E}-1$ & $-6.76 \mathrm{E} 00$ & $-5.69 \mathrm{E} 00$ & $2.16 \mathrm{E}+1$ \\
\hline \multirow[t]{2}{*}{55} & FE/FMBE & $1.68 \mathrm{E}+1$ & $4.54 \mathrm{E} 00$ & $1.64 \mathrm{E} 00$ & $-2.23 \mathrm{E}+1$ & $-1.78 \mathrm{E}+1$ & $6.81 \mathrm{E}+1$ \\
\hline & & $1.69 \mathrm{E}+1$ & $4.55 \mathrm{E} 00$ & 1.68E00 & $-2.24 \mathrm{E}+1$ & $-1.75 \mathrm{E}+1$ & $6.55 \mathrm{E}+1$ \\
\hline \multirow[t]{2}{*}{60} & $\mathrm{FE} / \mathrm{FMBE}$ & $-7.58 \mathrm{E} 00$ & $-2.16 \mathrm{E} 00$ & $-6.87 \mathrm{E}-1$ & 8.73E00 & $6.58 \mathrm{E} 00$ & $-2.62 \mathrm{E}+1$ \\
\hline & & $-7.55 \mathrm{E} 00$ & $-2.16 \mathrm{E} 00$ & $-7.05 \mathrm{E}-1$ & $8.76 \mathrm{E} 00$ & 6.67E00 & $-2.74 \mathrm{E}+1$ \\
\hline \multirow[t]{2}{*}{65} & FE/FMBE & $-1.03 \mathrm{E} 00$ & $-3.92 \mathrm{E}-1$ & $-1.74 \mathrm{E}-1$ & $4.25 \mathrm{E}-1$ & $3.18 \mathrm{E}-2$ & $-2.75 \mathrm{E}-1$ \\
\hline & & $-1.02 \mathrm{E} 00$ & $-3.94 \mathrm{E}-1$ & $-1.74 \mathrm{E}-1$ & $4.37 \mathrm{E}-1$ & $7.43 \mathrm{E}-2$ & $-8.80 \mathrm{E}-1$ \\
\hline \multirow[t]{2}{*}{70} & $\mathrm{FE} / \mathrm{FMBE}$ & $6.89 \mathrm{E}+1$ & $2.18 \mathrm{E}+1$ & $3.44 \mathrm{E} 00$ & $-9.16 \mathrm{E}+1$ & $-7.00 \mathrm{E}+1$ & $3.38 \mathrm{E}+2$ \\
\hline & & $7.25 \mathrm{E}+1$ & $2.19 \mathrm{E}+1$ & $3.65 \mathrm{E} 00$ & $-9.18 \mathrm{E}+1$ & $-6.41 \mathrm{E}+1$ & $2.79 \mathrm{E}+2$ \\
\hline \multirow[t]{2}{*}{75} & $\mathrm{FE} / \mathrm{FMBE}$ & $-6.91 \mathrm{E} 00$ & $-2.38 \mathrm{E} 00$ & $-3.79 \mathrm{E}-1$ & $8.28 \mathrm{E} 00$ & 5.93E00 & $-2.29 \mathrm{E}+1$ \\
\hline & & $-6.85 \mathrm{E} 00$ & $-2.38 \mathrm{E} 00$ & $-3.97 \mathrm{E}-1$ & $8.29 \mathrm{E} 00$ & $6.01 \mathrm{E} 00$ & $-2.33 \mathrm{E}+1$ \\
\hline \multirow[t]{2}{*}{80} & FE/FMBE & $7.59 \mathrm{E}+1$ & $2.93 \mathrm{E}+1$ & 2.39E00 & $-1.06 \mathrm{E}+2$ & $-7.75 \mathrm{E}+1$ & $4.21 \mathrm{E}+2$ \\
\hline & & $8.07 \mathrm{E}+1$ & $2.92 \mathrm{E}+1$ & 2.61E00 & $-1.05 \mathrm{E}+2$ & $-6.82 \mathrm{E}+1$ & $3.12 \mathrm{E}+2$ \\
\hline \multirow[t]{2}{*}{85} & FE/FMBE & $-4.16 \mathrm{E} 00$ & $-1.73 \mathrm{E} 00$ & $-2.01 \mathrm{E}-1$ & $4.89 \mathrm{E} 00$ & $3.20 \mathrm{E} 00$ & $-1.23 \mathrm{E}+1$ \\
\hline & & $-4.02 \mathrm{E} 00$ & $-1.69 \mathrm{E} 00$ & $-2.13 \mathrm{E}-1$ & $4.75 \mathrm{E} 00$ & $3.14 \mathrm{E} 00$ & $-1.22 \mathrm{E}+1$ \\
\hline \multirow[t]{2}{*}{90} & FE/FMBE & $-7.87 \mathrm{E} 00$ & $-3.72 \mathrm{E} 00$ & $-2.40 \mathrm{E}-1$ & $1.06 \mathrm{E}+1$ & 7.01E00 & $-2.55 \mathrm{E}+1$ \\
\hline & analytical & $-7.73 \mathrm{E} 00$ & $-3.73 \mathrm{E} 00$ & $-2.71 \mathrm{E}-1$ & $1.07 \mathrm{E}+1$ & 7.40E00 & $-2.80 \mathrm{E}+1$ \\
\hline \multirow[t]{2}{*}{95} & FE/FMBE & $-6.55 \mathrm{E}+1$ & $-3.55 \mathrm{E}+1$ & $-9.64 \mathrm{E}-1$ & $1.00 \mathrm{E}+2$ & $6.73 \mathrm{E}+1$ & $-1.68 \mathrm{E}+2$ \\
\hline & & $-8.85 \mathrm{E}+1$ & $-5.63 \mathrm{E}+1$ & $-1.77 \mathrm{E} 00$ & $1.63 \mathrm{E}+2$ & $1.71 \mathrm{E}+2$ & $-4.33 \mathrm{E}+2$ \\
\hline \multirow[t]{2}{*}{100} & FE/FMBE & $-1.44 \mathrm{E} 00$ & $-6.53 \mathrm{E}-1$ & $-5.44 \mathrm{E}-2$ & 1.11E00 & $4.93 \mathrm{E}-1$ & $3.40 \mathrm{E}+1$ \\
\hline & analytical & $2.14 \mathrm{E} 00$ & 1.23E00 & $-8.04 \mathrm{E}-2$ & $-3.90 \mathrm{E} 00$ & $-2.29 \mathrm{E} 00$ & $1.14 \mathrm{E}+1$ \\
\hline
\end{tabular}

evaluation of displacement $\mathbf{u}$, sound pressure $\mathbf{p}$ and radiated sound power $P$. This effect is hardly visible in the error of the numerical solution if the solution is based on normalized sensitivities.

Table 5 presents the numerical errors based on normalized sound power sensitivity. Resonances are hardly recognizable except at the frequency range above $90 \mathrm{~Hz}$. Error remains moderate with some exceptions. The results should be suitable for an optimization process although the error is above $10 \%$ in numerous areas. However, the results at the highest frequency of $100 \mathrm{~Hz}$ are unacceptable in this sense. The sensitivities of four of the six parameters at this frequency exhibit a wrong algebraic sign, which is assumed to be attributed to the numerical limitations of the FE and BE meshes that only happen at the highest frequency point of the investigation.

Manual control of the step size for gradient evaluation of the structural system matrices in ANSYS is required to achieve acceptable accuracy. Although not investigated in detail, the assumed reason for this limitation involves the use of single precision real numbers 
Table 5. Relative errors of the normalized sensitivities of radiated sound power (\%).

\begin{tabular}{crrrrrr}
\hline$f$ in $[\mathrm{Hz}]$ & \multicolumn{1}{c}{$\bar{P}_{, \rho}$} & \multicolumn{1}{c}{$\bar{P}_{, \rho_{s}}$} & \multicolumn{1}{c}{$\bar{P}_{, \nu}$} & \multicolumn{1}{c}{$\bar{P}_{, E}$} & $\bar{P}_{, h}$ & $\bar{P}_{, r}$ \\
\hline 10 & 0.200 & 0.183 & 176 & 122 & 5.23 & 3.82 \\
20 & -0.0874 & 0.114 & 11.0 & 6.09 & 1.37 & 2.02 \\
30 & -0.230 & 0.103 & 5.54 & 0.892 & 0.693 & 3.05 \\
40 & 2.08 & 0.0963 & 18.6 & 0.184 & 0.558 & 6.15 \\
50 & -0.204 & 0.222 & -2.56 & 0.182 & 1.23 & 4.28 \\
55 & -0.839 & -0.183 & -2.53 & -0.158 & 1.50 & 3.93 \\
60 & 0.366 & -0.275 & -2.62 & -0.361 & -1.29 & -4.32 \\
65 & 1.07 & -0.550 & -0.386 & -2.74 & -57.2 & -68.7 \\
70 & -4.95 & -0.580 & -5.73 & -0.140 & 9.20 & 21.2 \\
75 & 0.866 & -0.0608 & -4.73 & -0.0623 & -1.44 & -1.90 \\
80 & -5.91 & 0.192 & -8.47 & 0.877 & 13.7 & 34.8 \\
85 & 3.46 & 2.32 & -5.43 & 2.91 & 1.60 & 0.949 \\
90 & 1.78 & -0.187 & -11.7 & -0.572 & -5.28 & -9.03 \\
95 & -26.0 & -36.9 & -45.5 & -38.7 & -60.6 & -61.1 \\
100 & -167 & -153 & -32.3 & -128 & -122 & 199 \\
\hline
\end{tabular}

for structural system matrices in ANSYS. However, the algorithm works reliable and is sufficiently accurate even with this limitation.

Figure 9 shows the comparison of the calculating time for the sensitivity analysis, where the design variables are set as fluid density, structural density, thickness of the shell and the radius of the shell. "AOM" denotes the adjoint operator method and "DDM" denotes the direct differentiation method. The CPU time increases with the degree of the freedom increase, and the CPU time for the AOM is smaller than that for the DDM. When the DDM is applied, the coupled equation needs to be solved repeatedly for different design

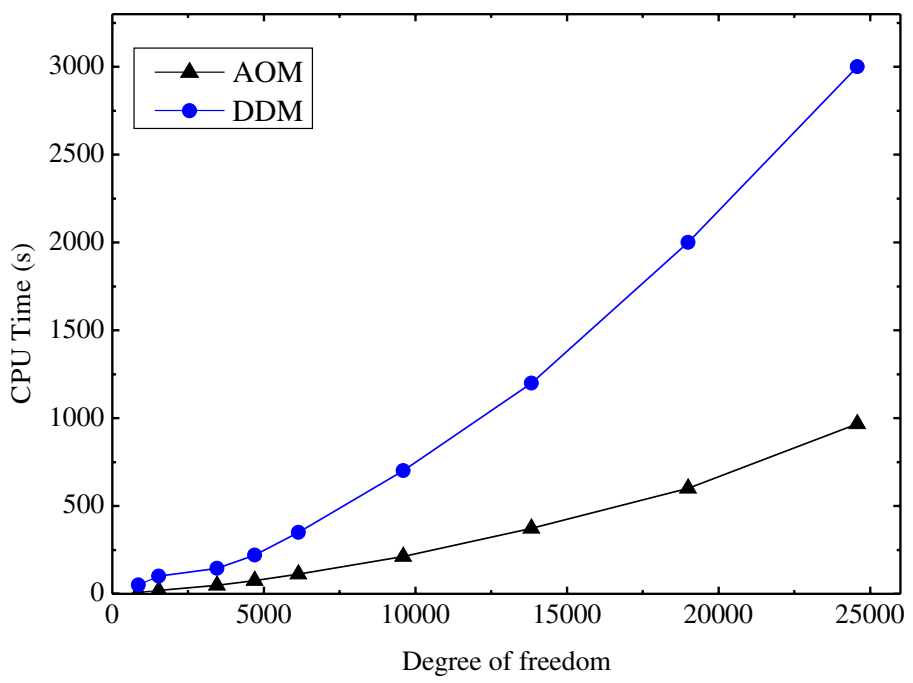

Fig. 9. The comparison of the calculating time for the sensitivity analysis. 


\section{Chen et al.}

variables. So, the linear system of equation needs to be solved for $m$ times for $m$ design variables. However, when the AOM is applied, the linear system of equations only needs to be solved once for different design variables. For problems with many design variables, AOM requires less computational costs and performs more efficiently than DDM.

\section{An Example of Closed Elastic Cylindrical Shell}

In this example, the immersed structure is a cylindrical shell with radius $r=1.0 \mathrm{~m}$ centered at point $(0,0,0)$, the length of the cylindrical shell is $9 \mathrm{~m}$, the radius of the half-spherical shell on the right side of the cylindrical shell is also set to $r$, the length of the conical shell on the left side of the cylindrical shell is set to $2 \mathrm{~m}$ and the radius is set to $0.5 \mathrm{~m}$ and $1 \mathrm{~m}$, respectively, as shown in Fig. 10. The thickness is $0.01 \mathrm{~m}$, Young's modulus $2.1 \times 10^{11} \mathrm{~Pa}$, Poisson's ratio 0.3 and the density $7860 \mathrm{~kg} / \mathrm{m}^{3}$. For the fluid, the density is $1000 \mathrm{~kg} / \mathrm{m}^{3}$ and the speed of sound $1482 \mathrm{~m} / \mathrm{s}$. The surface of the shell is discretized with 23040 quadrilateral elements.

\subsection{Acoustic scattering}

In this subsection, we consider the acoustic scattering of a plane incident wave with unit amplitude on the closed elastic cylindrical shell, and the plane incident wave is traveling along the positive $\mathbf{x}$-axis. Figure 11 compares the sound pressure for rigid and elastic analyses at a point $(-50,0,0)$. As step size of $1 \mathrm{~Hz}$ up to $300 \mathrm{~Hz}$ is used for evaluation of the numerical solution. The coupled element FE/FMBE is used for the elastic analyses, and FMBE for the rigid analyses. This figure shows that the solution for elastic analysis largely deviates from the solution for rigid analysis. This result denotes that the fluid-structure interaction has a considerable impact on the vibration response for the thin shell structure.

Figure 12 shows the sound pressure sensitivity with respect to the thickness of the shell at a point $(-50,0,0)$. The solution for FE/FMBE has a good agreement with that for $\mathrm{FE} / \mathrm{BE}$. This result denotes that the use of the fast multipole method not only decreases the computing time and the memory storage, but also maintains the high accuracy characteristic of the conventional BEM.

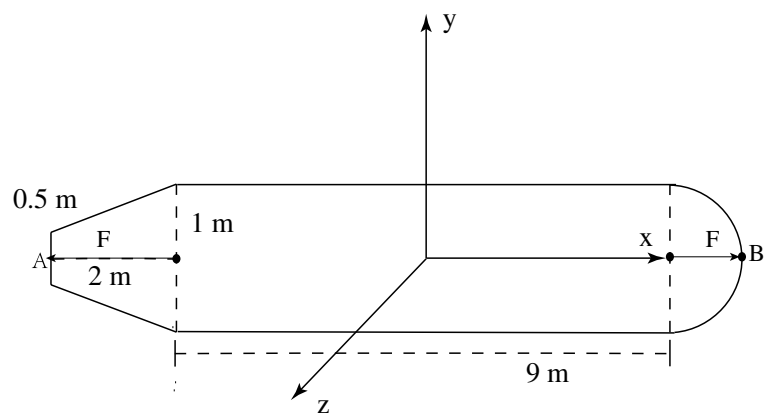

Fig. 10. An elastic cylindrical shell with a half-spherical shell and a conical shell. 


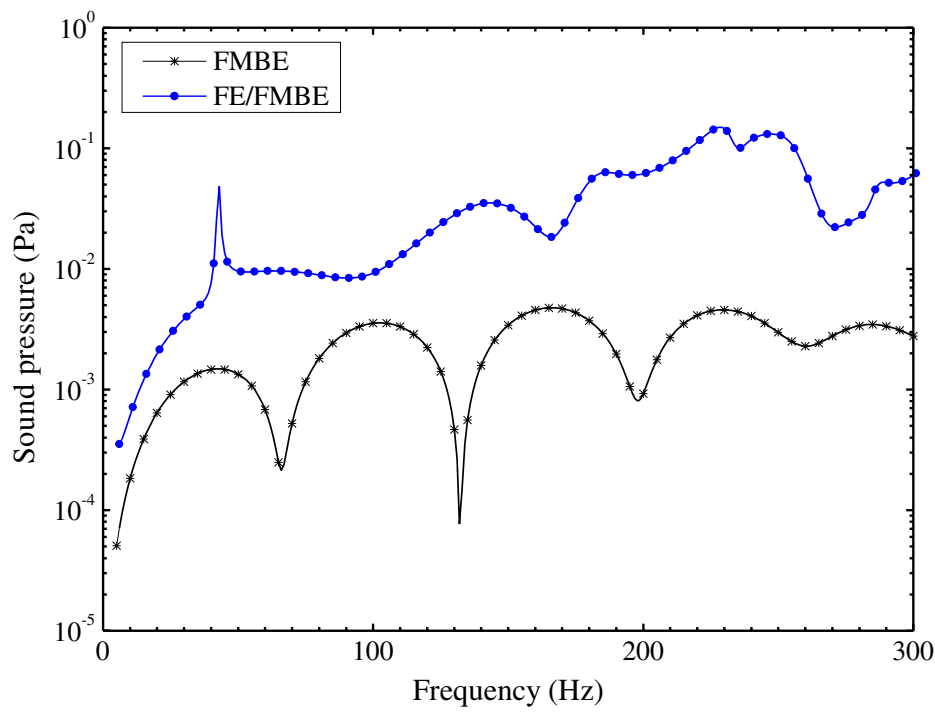

Fig. 11. Sound pressure at a computing point $(-50,0,0)$.

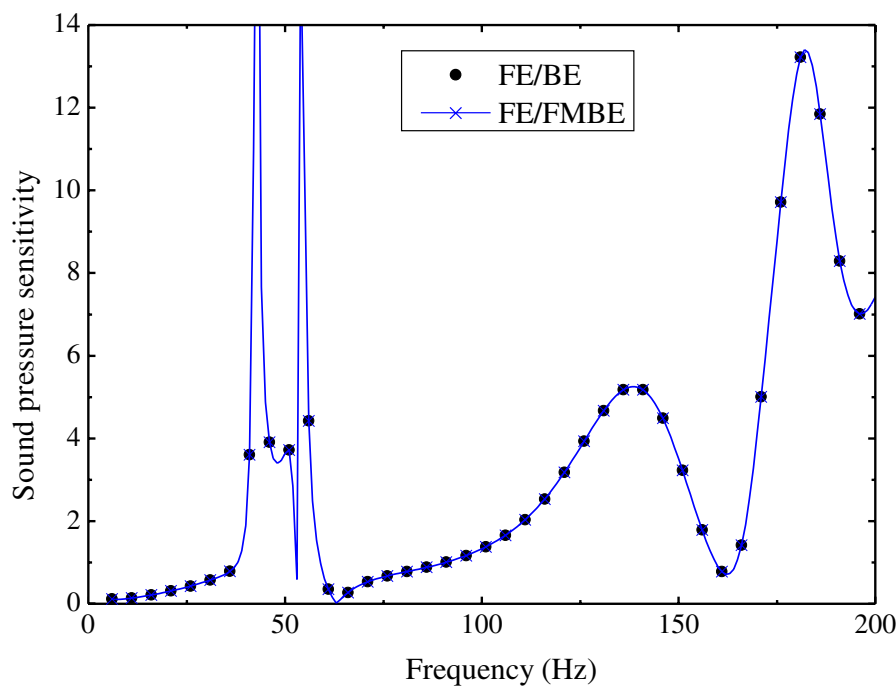

Fig. 12. Sound pressure sensitivity with respect to the thickness of the shell at point $(-50,0,0)$.

The CPU time used to calculate the acoustic pressure value at point $(-50,0,0)$ is plotted in Fig. 13, where "BE" and "FMBE" denote the solutions calculated by conventional BEM and FMBEM algorithm when interaction between fluid and structure is not taken into account (rigid analysis). From this figure, one can see that elastic analysis needs much more time than rigid analysis. In fact, for the elastic analysis in every iteration step one needs to solve the system of linear equation $\mathbf{A x}=\mathbf{y}$ to obtain the solution of $\mathbf{A}^{-\mathbf{1}} \mathbf{y}$ and this is very expensive. So in order to solve efficiently $\mathbf{A x}=\mathbf{y}$, the development of a more suitable 
L. Chen et al.

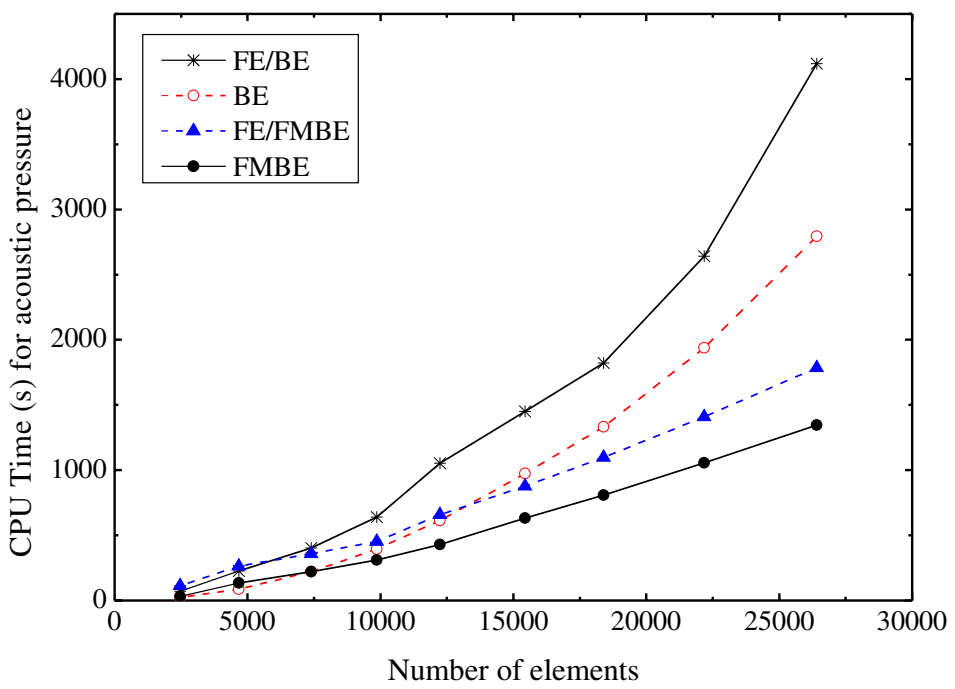

Fig. 13. CPU time used to calculate the sound pressure with $f=50 \mathrm{~Hz}$ at point $(-50,0,0)$.

solving method is required. It can also be seen in this figure that FE/FMBE algorithm has higher efficiency for three-dimensional fluid-structure interaction analysis.

\subsection{Acoustic radiation}

In this subsection, the immersed structure is excited by two concentrated forces $F$ with unit amplitude at points $A$ and $B$, as shown in Fig. 10. Figure 14 shows the radiated sound power solution on the structural surface with frequency increases. A step size of $1 \mathrm{~Hz}$ up to $300 \mathrm{~Hz}$ is used for evaluation of the numerical solution. In this figure, "Uncouple" denotes

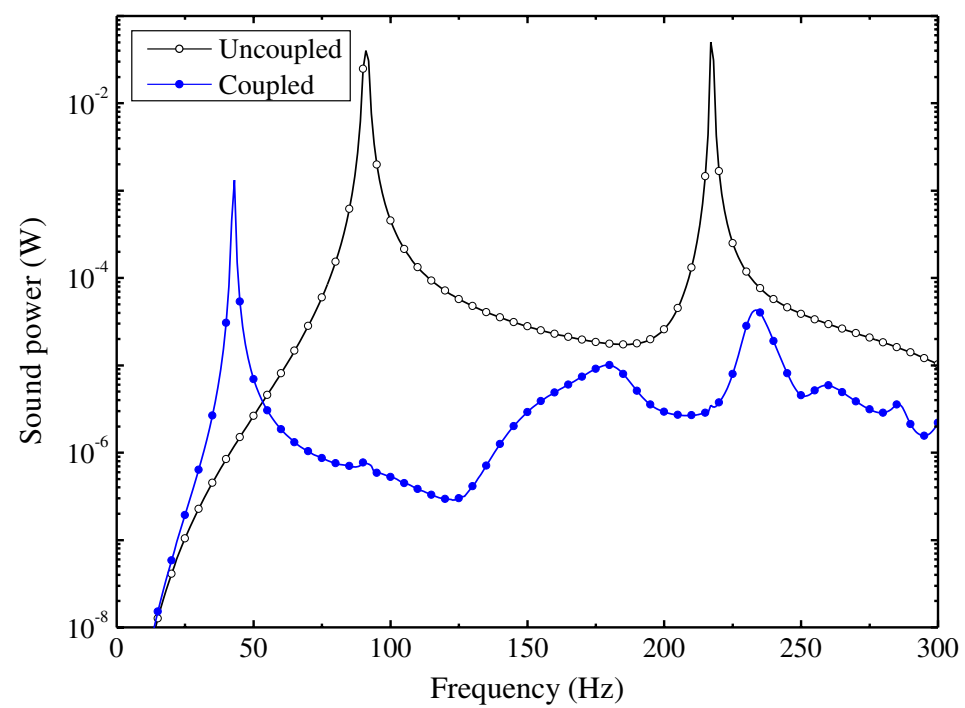

Fig. 14. Sound power on the structural surface with respect to frequency. 


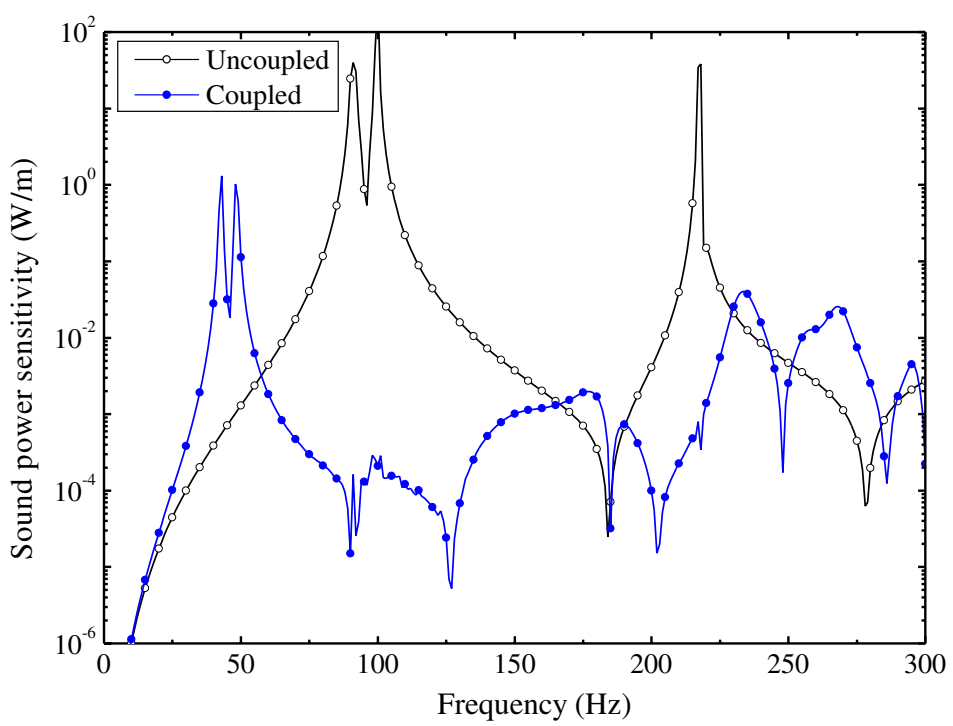

Fig. 15. Sound power sensitivity with respect to the thickness of the shell.

the numerical solution for the radiated sound power when the interaction between the fluid and the structure is not taken into account, and "Couple" denotes the numerical solution for the radiated sound power under couple. This figure shows that the solution for "Uncouple" largely deviates from the solution for "Couple." Figure 15 shows the radiated sound power sensitivity solution on the structural surface, where the design variable is set as the thickness of the shell. Similarly, this figure shows that the solution for "Uncouple" largely deviates from the solution for "Couple." This result denotes that the fluid-structure interaction has a considerable impact on the vibration response for the thin shell structure.

\section{Conclusions}

This study presents an effective algorithm for computing the sound power sensitivity of fully coupled structural-acoustic systems. The key point of this algorithm is the development of the adjoint operator approach, where the design variable can be arbitrarily chosen (e.g. material data of fluid and structure, shape modifying parameters, and other features such as shell thickness). The formulations for different categories of the variables differ from one another only through the formulation of column matrix $\mathbf{r}$ in Eq. (15) and the second term in Eq. (19). The main computational expenditure for the sensitivity analysis is that the solution of the adjoint system of equations in Eq. (20) is required only once to evaluate the entire gradient. Thus, the proposed adjoint operator shows higher efficiency for the sensitivity analysis with multiple design variables. Numerical examples are presented to demonstrate the validity and correctness of the presented algorithm. Although direct differentiation allows an analytical sensitivity evaluation of one parameter (i.e. fluid density), a semi-analytical approach is used for the structural parameters. 


\section{Chen et al.}

The algorithm presented in this study makes it possible to predict numerically the effects of different design variables on the sound field for large-scale practical problems. Future work will include applying the structural-acoustic design sensitivity analysis to optimize 3D practical problems. This method will be of particular importance for optimization problems with many design variables.

\section{Acknowledgments}

The authors acknowledge the financial support from the China Scholarship Council, the National Natural Science Foundation of China (Grant No. 11172291), the Research Fund for the Doctoral Program of Higher Education of China (Grant No. 20133402110036), and USTC (Grant No. WK2090000007).

\section{References}

1. S. Marburg, Developments in structural-acoustic optimization for passive noise control, Arch. Comput. Methods Eng. 27 (2002) 291-370.

2. J. S. Lamancusa, Numerical optimization techniques for structural-acoustic design of rectangular panels, Compos. Struct. 48 (1993) 661-675.

3. S. A. Hambric, Sensitivity calculations for broad-band acoustic radiated noise design optimization problems, J. Vib. Acoust. 118 (1996) 529-532.

4. S. Marburg and H.-J. Hardtke, Shape optimization of a vehicle hat-shelf: Improving acoustic properties for different load-cases by maximizing first eigenfrequency, Compos. Struct. 79 (2001) 1943-1957.

5. R. T. Haftka and H. M. Adelman, Recent developments in structural sensitivity analysis, Struct. Optim. 1 (1989) 137-151.

6. S. Marburg, Efficient optimization of a noise transfer function by modification of a shell structure geometry. Part I: Theory, Struct. Multidiscip. Optim. 24 (2002) 51-59.

7. L. L. Chen, H. B. Chen and C. J. Zheng, FEM/wideband FMBEM coupling for fluid-structure interaction problem and 2D acoustic design sensitivity analysis, Comput. Model. Eng. Sci. 94(6) (2013) 459-483.

8. L. L. Chen, C. J. Zheng and H. B. Chen, FEM/wideband FMBEM coupling for structuralacoustic design sensitivity analysis, Comput. Methods Appl. Mech. Eng. 276 (2014) 1-19.

9. K. K. Choi, I. Shim and S. Wang, Design sensitivity analysis of structure-induced noise and vibration, J. Vib. Acoust. 119 (1997) 173-179.

10. S. Wang, Design sensitivity analysis of noise, vibration and harshness of vehicle body structure, Mech. Struct. Mach. 27 (1999) 317-336.

11. S. Marburg and B. Nolte (eds.), Computational Acoustics of Noise Propagation in Fluids: Finite and Boundary Element Methods (Springer, Berlin, 2008).

12. D. Fritze, S. Marburg and H.-J. Hardtke, FEM-BEM-coupling and structural-acoustic sensitivity analysis for shell geometries, Comput. Struct. 82 (2005) 143-154.

13. G. C. Everstine and F. M. Henderson, Coupled finite element/boundary element approach for fluid-structure interaction, J. Acoust. Soc. Am. 87 (1990) 1938-1947.

14. S. Merz, R. Kinns and N. Kessissoglou, Structural and acoustic responses of a submarine hull due to propeller forces, J. Sound Vib. 325 (2009) 266-286.

15. Z. S. Chen, G. Hofstetter and H. A. Mang, A Galerkin-type BE-FE formulation for elasticacoustic coupling, Comput. Methods Appl. Mech. Eng. 152 (1998) 147-155. 
16. S. Merz, N. Kessissoglou, R. Kinns and S. Marburg, Passive and active control of the radiated sound power from a submarine excited by propeller forces, J. Ship Res. 57 (2013) 59-71.

17. H. Peters, N. Kessissoglou and S. Marburg, Modal decomposition of exterior acoustic-structure interaction, J. Acoust. Soc. Am. 133 (2013) 2668-2677.

18. H. Peters, S. Marburg and N. Kessissoglou, Structural-acoustic coupling on non-conforming meshes with quadratic shape functions, Int. J. Numer. Methods Eng. 91 (2012) 27-38.

19. Y. Saad, Iterative Methods for Sparse Linear Systems (PWS Publishing Company, Boston, 1996).

20. S. Marburg and S. Schneider, Performance of iterative solvers for acoustic problems. Part I: Solvers and effect of diagonal preconditioning, Eng. Anal. Bound. Elem. 27 (2003) 714-725.

21. L. Greengard and V. Rokhlin, A fast algorithm for particle simulations, J. Comput. Phys. 73 (1987) 325-348.

22. R. Coifman, V. Rokhlin and S. Wandzura, The fast multipole method for the wave equation: A pedestrian prescription, IEEE Antennas Propag. Mag. 35 (1993) 7-12.

23. S. Schneider, Application of fast methods for acoustic scattering and radiation problems, $J$. Comput. Acoust. 11(3) (2003) 387-401.

24. S. Schneider and S. Marburg, Performance of iterative solvers for acoustic problems. Part II: Acceleration by ilu-type preconditioner, Eng. Anal. Bound. Elem. 27(7) (2003) 751-757.

25. T. Sakuma and Y. Yasuda, Fast multipole boundary element method for large-scale steady-state sound field analysis, Part I: Setup and validation, Acustica/Acta Acustica 88 (2002) 513-525.

26. L. Shen and Y. J. Liu, An adaptive fast multipole boundary element method for threedimensional acoustic wave problems based on the Burton-Miller formulations, Comput. Mech. 40 (2007) 461-472.

27. L. L. Chen, C. J. Zheng and H. B. Chen, A wideband FMBEM for 2D acoustic design sensitivity analysis based on direct differentiation method, Comput. Mech. 52 (2013) 631-648.

28. C. J. Zheng, T. Matsumoto, T. Takahashi and H. B. Chen, Explicit evaluation of hypersingular boundary integral equations for acoustic sensitivity analysis based on direct differentiation method, Eng. Anal. Bound. Elem. 35 (2011) 1225-1235.

29. C. J. Zheng, T. Matsumoto, T. Takahashi and H. B. Chen, A wideband fast multipole boundary element method for three dimensional acoustic shape sensitivity analysis based on direct differentiation method, Eng. Anal. Bound. Elem. 36 (2012) 361-371.

30. M. Bebendorf and S. Rjasanow, Adaptive low-rank approximation of collocation matrices, Computing 70 (2003) 1-24.

31. M. Bebendorf and R. Grzhibovskis, Accelerating Galerkin BEM for linear elasticity using adaptive cross approximation, Math. Methods Appl. Sci. 29 (2006) 1721-1747.

32. L. L. Chen, C. J. Zheng, H. B. Chen and S. Marburg, Structuralacoustic sensitivity analysis of radiated sound power using a finite element/discontinuous fast multipole boundary element scheme, Int. J. Numer. Methods Fluids, Published online, doi: 10.1002/fld.4244.

33. S. Schneider, FE/FMBE coupling to model fluid-structure interaction, Int. J. Numer. Methods Eng. 76 (2008) 2137-2156.

34. D. Brunner, M. Junge and L. Gaul, A comparison of FE-BE coupling schemes for large-scale problems with fluid-structure interaction, Int. J. Numer. Methods Eng. 77 (2009) 664-688.

35. M. Fischer and L. Gaul, Fast BEM-FEM mortar coupling for acoustic-structure interaction, Int. J. Numer. Methods Eng. 62 (2005) 1677-1690.

36. M. Junge, D. Brunner and L. Gaul, Solution of FE-BE coupled eigenvalue problems for the prediction of the vibro-acoustic behavior of ship-like structures, Int. J. Numer. Methods Eng. 87 (2011) 664-676.

37. S. Merz, N. Kessissoglou, R. Kinns and S. Marburg, Minimisation of the sound power radiated by a submarine through optimisation of its resonance changer, J. Sound Vib. 329 (2010) 980-993. 
38. S. Marburg and B. Nolte, A unified approach to finite and boundary element discretization in linear time-harmonic acoustics, in Computational Acoustics of Noise Propagation in Fluids: Finite and Boundary Element Methods, Chap. 0 (Springer, Berlin, 2008), pp. 1-34.

39. S. Marburg and R. Anderssohn, Fluid structure interaction and admittance boundary conditions: Setup of an analytical example, J. Comput. Acoust. 19 (2011) 63-74.

40. O. Dazel, F. Sgard and C. H. Lamarque, Application of generalized complex modes to the calculation of the forced response of three-dimensional poroelastic materials, J. Sound Vib. 268 (2003) 555-580.

41. G. C. Gaunaurd and H. Überall, RST analysis of monostatic and bistatic acoustic echoes from an elastic sphere, J. Acoust. Soc. Am. 73 (1983) 1-12.

42. M. C. Junger and D. Feit, Structures and Their Interaction (The MIT Press, Cambridge, Massachusetts, 1986).

43. ANSYS Academic Research, Release 14.5, Help System, Ansys Mechanical APDL, ANSYS, (2013). 